Article

\title{
Reduction of Prediction Errors for the Matrix Converter with an Improved Model Predictive Control
}

\author{
Shuang Feng ${ }^{1,2}$, Chaofan Wei ${ }^{1,2}$ and Jiaxing Lei ${ }^{1,2, *(D)}$ \\ 1 School of Electrical Engineering, Southeast University, Nanjing 210096, China \\ 2 Jiangsu Provincial Key Laboratory of Smart Grid Technology and Equipment, Southeast University, \\ Nanjing 210096, China \\ * Correspondence: jxlei@seu.edu.cn; Tel.: +86-151-5186-5550
}

Received: 8 June 2019; Accepted: 5 August 2019; Published: 6 August 2019

check for updates

\begin{abstract}
In this paper, an improved model predictive control (MPC) is proposed for the matrix converter (MC). First, the conventional MPC which adopts the separately discretized prediction models is discussed. It shows that the conventional MPC ignores the input-output interaction in every sampling period. Consequently, additional prediction errors arise, resulting in more current harmonics. Second, the principle of the improved MPC is presented. With the interaction considered, the integral state-space equation of the whole MC system is constructed and discretized to obtain the precise model. The eigenvalue analysis shows that the proposed prediction model has the same eigenvalues with the continuous model, and thus is more accurate than the conventional one to describe the MC's behavior in every sampling period. Finally, experimental results under various working conditions prove that the proposed approach can always increase the control accuracy and reduce the harmonic distortions, which in turn requires smaller filter components.
\end{abstract}

Keywords: matrix converter; model predictive control; prediction model; prediction error; current harmonics

\section{Introduction}

The matrix converter (MC) achieves direct AC-AC power conversion without large DC-link energy storage elements [1], as shown in Figure 1. After decades of continuous academic research [1-5], its commercialization has gained attention from industry. The Yaskawa Company has launched at least two series of MC products featuring high power quality, high efficiency, high power density, and energy regeneration.

As the $\mathrm{MC}$ is composed of nine bidirectional AC switches connecting every input phase to output phase without intermediate energy storage elements, controlling the MC is relatively complicated compared to the typical voltage source converters and has been an important issue since the birth of the MC. Linear control algorithms based on the PWM (Pulse Width Modulation) technique have been well developed for the $\mathrm{MC}$, which can achieve superior control performance and are widely adopted for the MC $[2,3,6,7]$. However, the duty cycle calculation is relatively complicated to implement in practice.

Benefiting from the fast development of semiconductor technology, model predictive control (MPC) has become a promising alternative to linear modulation algorithms [3,8]. Considering the discrete characteristic of a power converter, MPC calculates the cost function corresponding to each valid switching state and then applies the switching state that minimizes the cost function to the converter. Without the need of duty cycle calculations, MPC is easy to understand and implement. Featuring fast dynamic response and multi-objective optimization, MPC has attracted attention from researchers in various fields of power converters [9], including MCs. MPC can be applied to achieve 
normal operations of the MC, such as input reactive power minimization [10], sinusoidal input and output currents [11], direct power control [12], among others [13]. As MPC has the capability of multi-objective optimization, features such as motor torque control [14-17], speed control [18], common-mode voltage elimination [19], and efficiency improvement [20] can be easily included in MPC. Moreover, harmonic reduction [21], input active damping [22,23], over-modulation [24], and fault diagnosis $[25,26]$ can also be obtained based on MPC.

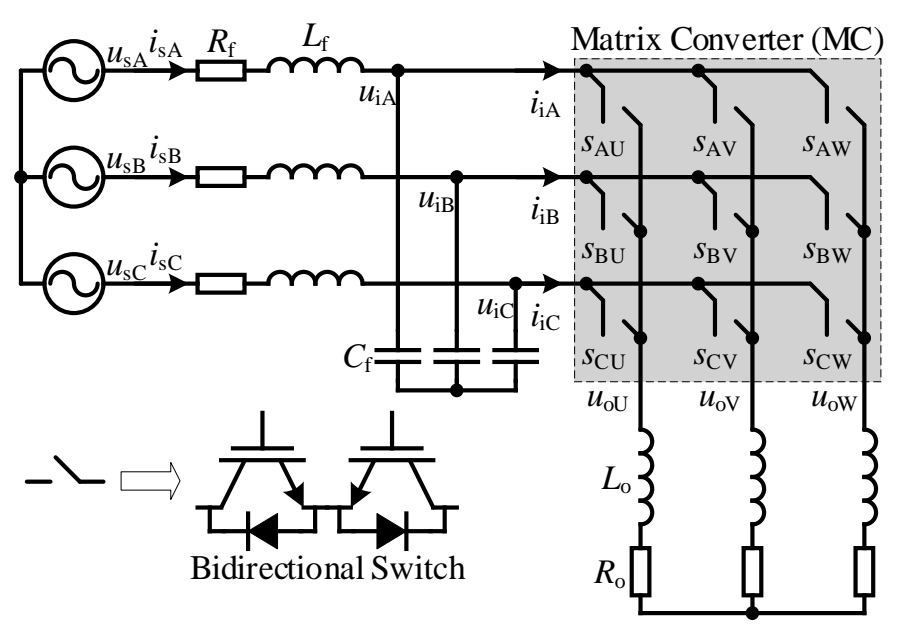

Figure 1. Basic schematic of the matrix converter (MC).

The application of existing MPC schemes to the MC is therefore a good idea, yet their implementation is not optimal. In practice, MPC is usually implemented in a digital signal controller and thus it relies on the discretized prediction model to describe the MC's behavior in every sampling period. All existing MPC schemes for the MC discretize the input and output circuits separately and consider the input and output prediction models fixed, irrespective of the MC's switching states. Due to the absence of large energy storage elements, currents and voltages on the input and output sides interact with each other directly. However, existing MPC schemes consider input voltages and output currents constant in one sampling period, ignoring the variations caused by the interaction. Consequently, they fail to accurately characterize the MC's behavior during each sampling period. This leads to increased prediction errors, especially under a large sampling period. For MPC, larger prediction errors always introduce more harmonics. This in turn requires larger filter components, which decreases the power density of the MC.

In this paper, an improved MPC scheme is proposed for the MC. The proposed MPC is based on a precise prediction model which considers the input circuit, MC, and output circuit as a whole system. The precise prediction model is obtained by discretizing the integral state-space equation of the whole MC system, with the interaction considered. Each valid switching state corresponds to a set of matrices of the precise prediction model. Compared with the conventional MPC which uses separate prediction models, the proposed approach adopts a precise prediction model which has the same eigenvalues as the continuous model of the whole MC system. Therefore, the proposed prediction model accurately characterizes the MC's behavior in every sampling period, as the interaction between the input and output circuits are considered. The proposed approach can thus achieve lower prediction errors, especially under a large sampling period, which in turn requires smaller filter components.

The rest of this paper is organized as follows. Section 2 introduces the conventional MPC with separate input and output prediction models. Section 3 presents the principle of the improved MPC based on the precise prediction model. Section 4 shows the experimental verification. Section 5 draws the conclusions. 


\section{Conventional MPC with Separate Prediction Models}

\subsection{Separate Input and Output Models in Continuous Domain}

Throughout this paper, the space vector characterizing a three-phase variable is defined as follows:

$$
x=x_{\alpha}+j x_{\beta}=\frac{2}{3}\left(x_{\mathrm{a}}+x_{\mathrm{b}} e^{j 2 \pi / 3}+x_{\mathrm{c}}{ }^{j 4 \pi / 3}\right),
$$

where vector $x$ represents any voltage or current vector at the input or output side of MC; $x_{\alpha}$ and $x_{\beta}$ are the $\alpha \beta$-axis components of $x$ in the two-phase stationary frame; and $x_{\mathrm{a}}, x_{\mathrm{b}}$, and $x_{\mathrm{c}}$ are the components in the three-phase stationary frame.

According to Figure 1, the continuous state-space equation for the input LC filter is the following:

$$
\frac{\mathrm{d}}{\mathrm{d} t}\left[\begin{array}{c}
i_{\mathrm{s}} \\
u_{\mathrm{i}}
\end{array}\right]=A_{\mathrm{i}}\left[\begin{array}{c}
i_{\mathrm{s}} \\
u_{\mathrm{i}}
\end{array}\right]+B_{\mathrm{i}}\left[\begin{array}{c}
u_{\mathrm{s}} \\
i_{\mathrm{i}}
\end{array}\right],
$$

where matrices $A_{\mathrm{i}}$ and $B_{\mathrm{i}}$ are expressed as follows:

$$
A_{\mathrm{i}}=\left[\begin{array}{cc}
-R_{\mathrm{f}} / L_{\mathrm{f}} & -1 / L_{\mathrm{f}} \\
1 / C_{\mathrm{f}} & 0
\end{array}\right], B_{\mathrm{i}}=\left[\begin{array}{cc}
1 / L_{\mathrm{f}} & 0 \\
0 & -1 / C_{\mathrm{f}}
\end{array}\right],
$$

where $R_{\mathrm{f}}$ is the parasitic resistance of input filter inductor $L_{\mathrm{f}}$ and $C_{\mathrm{f}}$ is the input filter capacitor. Similarly, the continuous model for the output circuit is the following:

$$
L_{\mathrm{O}} \frac{\mathrm{d} i_{\mathrm{o}}}{\mathrm{d} t}=u_{\mathrm{O}}-R_{\mathrm{o}} i_{\mathrm{O}}
$$

where $L_{\mathrm{o}}$ is the output filter inductor and $R_{\mathrm{O}}$ is the resistive load adopted in this paper; the parasitic resistance of $L_{\mathrm{o}}$ can be included in $R_{\mathrm{o}}$. The work in this paper is also applicable to other types of load only if the output circuit is modeled accordingly.

From Figure 1 and Equations (2) and (4), one can conclude that input currents and output voltages are the bonds between input and output circuits, satisfying the following:

$$
\left[\begin{array}{l}
u_{\mathrm{oU}} \\
u_{\mathrm{oV}} \\
u_{\mathrm{oW}}
\end{array}\right]=\left[\begin{array}{lll}
s_{\mathrm{AU}} & s_{\mathrm{BU}} & s_{\mathrm{CU}} \\
s_{\mathrm{AV}} & s_{\mathrm{BV}} & s_{\mathrm{CV}} \\
s_{\mathrm{AW}} & s_{\mathrm{BW}} & s_{\mathrm{CW}}
\end{array}\right]\left[\begin{array}{c}
u_{\mathrm{iA}} \\
u_{\mathrm{iB}} \\
u_{\mathrm{iC}}
\end{array}\right]=T_{\mathrm{MC}}\left[\begin{array}{c}
u_{\mathrm{iA}} \\
u_{\mathrm{iB}} \\
u_{\mathrm{iC}}
\end{array}\right],
$$

and

$$
\left[\begin{array}{c}
i_{\mathrm{iA}} \\
i_{\mathrm{iB}} \\
i_{\mathrm{iC}}
\end{array}\right]=T_{\mathrm{MC}}^{\mathrm{T}}\left[\begin{array}{c}
i_{\mathrm{oU}} \\
i_{\mathrm{oV}} \\
i_{\mathrm{oW}}
\end{array}\right],
$$

where $s_{x y}(x \in\{\mathrm{A}, \mathrm{B}, \mathrm{C}\}, y \in\{\mathrm{U}, \mathrm{V}, \mathrm{W}\})$ is 1 if the corresponding switch is closed and is 0 otherwise; $\boldsymbol{T}_{\mathrm{MC}}$ is the voltage transfer matrix of $\mathrm{MC}$; and superscript $\mathrm{T}$ represents the matrix transposition. Based on the Clarke transformation, Equations (7) and (8) can be deduced from Equations (5) and (6):

$$
\left[\begin{array}{l}
u_{\mathrm{o} \alpha} \\
u_{\mathrm{o} \beta}
\end{array}\right]=\left[\begin{array}{cc}
T_{\alpha \alpha} & T_{\alpha \beta} \\
T_{\beta \alpha} & T_{\beta \beta}
\end{array}\right]\left[\begin{array}{c}
u_{\mathrm{i} \alpha} \\
u_{\mathrm{i} \beta}
\end{array}\right]=T_{\mathrm{MC} \alpha \beta}\left[\begin{array}{c}
u_{\mathrm{i} \alpha} \\
u_{\mathrm{i} \beta}
\end{array}\right],
$$

and

$$
\left[\begin{array}{c}
i_{\mathrm{i} \alpha} \\
i_{\mathrm{i} \beta}
\end{array}\right]=T_{\mathrm{MC} \alpha \beta}^{\mathrm{T}}\left[\begin{array}{c}
i_{\mathrm{o} \alpha} \\
i_{\mathrm{o} \beta}
\end{array}\right]
$$


where the matrix $T_{\mathrm{MC} \alpha \beta}$ satisfies the following:

$$
T_{\mathrm{MC} \alpha \beta}=\frac{2}{3}\left[\begin{array}{ccc}
1 & -\frac{1}{2} & -\frac{1}{2} \\
0 & \frac{\sqrt{3}}{2} & -\frac{\sqrt{3}}{2}
\end{array}\right] \boldsymbol{T}_{\mathrm{MC}}\left[\begin{array}{cc}
1 & 0 \\
-\frac{1}{2} & \frac{\sqrt{3}}{2} \\
-\frac{1}{2} & -\frac{\sqrt{3}}{2}
\end{array}\right] .
$$

According to the principle of the MC, there are 27 valid switching states in total, as listed in Table 1. Each switching state corresponds to a value of the transfer matrix $T_{\mathrm{MC} \alpha \beta}$.

Table 1. Valid switching states of the MC.

\begin{tabular}{|c|c|c|c|c|c|c|c|}
\hline \multirow{2}{*}{$\begin{array}{c}\text { No. } \\
1\end{array}$} & \multicolumn{3}{|c|}{ On Switches } & \multirow{2}{*}{$\begin{array}{c}T_{\alpha \alpha} \\
1\end{array}$} & \multirow{2}{*}{$\begin{array}{c}T_{\alpha \beta} \\
-\sqrt{3} / 3\end{array}$} & \multirow{2}{*}{$\begin{array}{c}T_{\beta \alpha} \\
0\end{array}$} & \multirow{2}{*}{$\begin{array}{c}T_{\beta \beta} \\
0\end{array}$} \\
\hline & $\mathrm{S}_{\mathrm{AU}}$ & $\mathrm{S}_{\mathrm{BV}}$ & $\mathrm{S}_{\mathrm{BW}}$ & & & & \\
\hline 2 & $\mathrm{~S}_{\mathrm{BU}}$ & $\mathrm{S}_{\mathrm{AV}}$ & $\mathrm{S}_{\mathrm{AW}}$ & -1 & $\sqrt{3} / 3$ & 0 & 0 \\
\hline 3 & $\mathrm{~S}_{\mathrm{BU}}$ & $\mathrm{S}_{\mathrm{CV}}$ & $\mathrm{S}_{\mathrm{CW}}$ & 0 & $2 / \sqrt{3}$ & 0 & 0 \\
\hline 4 & $\mathrm{~S}_{\mathrm{CU}}$ & $S_{\mathrm{BV}}$ & $\mathrm{S}_{\mathrm{BW}}$ & 0 & $-2 / \sqrt{3}$ & 0 & 0 \\
\hline 5 & $\mathrm{~S}_{\mathrm{CU}}$ & $\mathrm{S}_{\mathrm{AV}}$ & $\mathrm{S}_{\mathrm{AW}}$ & -1 & $-\sqrt{3} / 3$ & 0 & 0 \\
\hline 6 & $\mathrm{~S}_{\mathrm{AU}}$ & $\mathrm{S}_{\mathrm{CV}}$ & $\mathrm{S}_{\mathrm{CW}}$ & 1 & $\sqrt{3} / 3$ & 0 & 0 \\
\hline 7 & $\mathrm{~S}_{\mathrm{BU}}$ & $\mathrm{S}_{\mathrm{AV}}$ & $\mathrm{S}_{\mathrm{BW}}$ & $-1 / 2$ & $\sqrt{3} / 6$ & $\sqrt{3} / 2$ & $-1 / 2$ \\
\hline 8 & $\mathrm{~S}_{\mathrm{AU}}$ & $S_{B V}$ & $\mathrm{~S}_{\mathrm{AW}}$ & $1 / 2$ & $-\sqrt{3} / 6$ & $-\sqrt{3} / 2$ & $1 / 2$ \\
\hline 9 & $\mathrm{~S}_{\mathrm{CU}}$ & $\mathrm{S}_{\mathrm{BV}}$ & $\mathrm{S}_{\mathrm{CW}}$ & 0 & $-\sqrt{3} / 3$ & 0 & 1 \\
\hline 10 & $\mathrm{~S}_{\mathrm{BU}}$ & $\mathrm{S}_{\mathrm{CV}}$ & $\mathrm{S}_{\mathrm{BW}}$ & 0 & $\sqrt{3} / 3$ & 0 & -1 \\
\hline 11 & $\mathrm{~S}_{\mathrm{AU}}$ & $\mathrm{S}_{\mathrm{CV}}$ & $\mathrm{S}_{\mathrm{AW}}$ & $1 / 2$ & $\sqrt{3} / 6$ & $-\sqrt{3} / 2$ & $-1 / 2$ \\
\hline 12 & $\mathrm{~S}_{\mathrm{CU}}$ & $\mathrm{S}_{\mathrm{AV}}$ & $\mathrm{S}_{\mathrm{CW}}$ & $-1 / 2$ & $-\sqrt{3} / 6$ & $\sqrt{3} / 2$ & $1 / 2$ \\
\hline 13 & $\mathrm{~S}_{\mathrm{BU}}$ & $\mathrm{S}_{\mathrm{BV}}$ & $\mathrm{S}_{\mathrm{AW}}$ & $-1 / 2$ & $\sqrt{3} / 6$ & $-\sqrt{3} / 2$ & $1 / 2$ \\
\hline 14 & $\mathrm{~S}_{\mathrm{AU}}$ & $\mathrm{S}_{\mathrm{AV}}$ & $\mathrm{S}_{\mathrm{BW}}$ & $1 / 2$ & $-\sqrt{3} / 6$ & $\sqrt{3} / 2$ & $-1 / 2$ \\
\hline 15 & $\mathrm{~S}_{\mathrm{CU}}$ & $\mathrm{S}_{\mathrm{CV}}$ & $\mathrm{S}_{\mathrm{BW}}$ & 0 & $-\sqrt{3} / 3$ & 0 & -1 \\
\hline 16 & $\mathrm{~S}_{\mathrm{BU}}$ & $S_{B V}$ & $\mathrm{~S}_{\mathrm{CW}}$ & 0 & $\sqrt{3} / 3$ & 0 & 1 \\
\hline 17 & $\mathrm{~S}_{\mathrm{AU}}$ & $\mathrm{S}_{\mathrm{AV}}$ & $\mathrm{S}_{\mathrm{CW}}$ & $1 / 2$ & $\sqrt{3} / 6$ & $\sqrt{3} / 2$ & $1 / 2$ \\
\hline 18 & $\mathrm{~S}_{\mathrm{CU}}$ & $\mathrm{S}_{\mathrm{CV}}$ & $\mathrm{S}_{\mathrm{AW}}$ & $-1 / 2$ & $-\sqrt{3} / 6$ & $-\sqrt{3} / 2$ & $-1 / 2$ \\
\hline 19 & $\mathrm{~S}_{\mathrm{AU}}$ & $\mathrm{S}_{\mathrm{AV}}$ & $\mathrm{S}_{\mathrm{AW}}$ & 0 & 0 & 0 & 0 \\
\hline 20 & $\mathrm{~S}_{\mathrm{BU}}$ & $S_{B V}$ & $\mathrm{~S}_{\mathrm{BW}}$ & 0 & 0 & 0 & 0 \\
\hline 21 & $\mathrm{~S}_{\mathrm{CU}}$ & $\mathrm{S}_{\mathrm{CV}}$ & $\mathrm{S}_{\mathrm{CW}}$ & 0 & 0 & 0 & 0 \\
\hline 22 & $\mathrm{~S}_{\mathrm{AU}}$ & $\mathrm{S}_{\mathrm{BV}}$ & $\mathrm{S}_{\mathrm{CW}}$ & 1 & 0 & 0 & 1 \\
\hline 23 & $\mathrm{~S}_{\mathrm{AU}}$ & $\mathrm{S}_{\mathrm{CV}}$ & $\mathrm{S}_{\mathrm{BW}}$ & 1 & 0 & 0 & -1 \\
\hline 24 & $\mathrm{~S}_{\mathrm{BU}}$ & $\mathrm{S}_{\mathrm{AV}}$ & $\mathrm{S}_{\mathrm{CW}}$ & $-1 / 2$ & $\sqrt{3} / 2$ & $\sqrt{3} / 2$ & $1 / 2$ \\
\hline 25 & $\mathrm{~S}_{\mathrm{BU}}$ & $\mathrm{S}_{\mathrm{CV}}$ & $\mathrm{S}_{\mathrm{AW}}$ & $-1 / 2$ & $\sqrt{3} / 2$ & $-\sqrt{3} / 2$ & $-1 / 2$ \\
\hline 26 & $\mathrm{~S}_{\mathrm{CU}}$ & $\mathrm{S}_{\mathrm{AV}}$ & $\mathrm{S}_{\mathrm{BW}}$ & $-1 / 2$ & $-\sqrt{3} / 2$ & $\sqrt{3} / 2$ & $-1 / 2$ \\
\hline 27 & $\mathrm{~S}_{\mathrm{CU}}$ & $\mathrm{S}_{\mathrm{BV}}$ & $\mathrm{S}_{\mathrm{AW}}$ & $-1 / 2$ & $-\sqrt{3} / 2$ & $-\sqrt{3} / 2$ & $1 / 2$ \\
\hline
\end{tabular}

\subsection{Input and Output Prediction Models}

The conventional MPC scheme obtains the prediction models for the input and output circuits by discretizing Equations (2) and (4) separately. This discretization method is intuitive and easy to understand, yet the control accuracy is not optimal, as discussed below.

According to Equation (2), the discrete model of the input circuit is the following:

$$
\left[\begin{array}{c}
\boldsymbol{i}_{\mathrm{S}}[k+1] \\
\boldsymbol{u}_{\mathrm{i}}[k+1]
\end{array}\right]=\boldsymbol{\Phi}_{\mathrm{i}}\left[\begin{array}{c}
\boldsymbol{i}_{\mathrm{S}}[k] \\
\boldsymbol{u}_{\mathrm{i}}[k]
\end{array}\right]+\boldsymbol{\Gamma}_{\mathrm{i}}\left[\begin{array}{c}
\boldsymbol{u}_{\mathrm{S}}[k] \\
\boldsymbol{i}_{\mathrm{i}}[k]
\end{array}\right]
$$

where matrices $\boldsymbol{\Phi}_{\mathrm{i}}$ and $\boldsymbol{\Gamma}_{\mathrm{i}}$ are expressed as follows:

$$
\boldsymbol{\Phi}_{\mathrm{i}}=e^{A_{\mathrm{i}} T_{\mathrm{s}}}, \boldsymbol{\Gamma}_{\mathrm{i}}=\boldsymbol{A}_{\mathrm{i}}^{-1}\left(\boldsymbol{\Phi}_{\mathrm{i}}-\boldsymbol{I}_{2 \times 2}\right) \boldsymbol{B}_{\mathrm{i}},
$$


where the zero-order hold $(\mathrm{ZOH})$ method is adopted in this paper to discretize the state-space equations; $x[k]$ represents the value of a variable $x$ at the beginning of the $k$ th sampling period; and $T_{\mathrm{s}}$ is the sampling time. Similarly, the discrete model for the output circuit is obtained from Equation (4) as follows:

$$
i_{\mathrm{o}}[k+1]=\boldsymbol{\Phi}_{\mathrm{o}} \boldsymbol{i}_{\mathrm{o}}[k]+\boldsymbol{\Gamma}_{\mathrm{o}} \boldsymbol{u}_{\mathrm{o}}[k],
$$

where coefficients $\boldsymbol{\Phi}_{\mathrm{o}}$ and $\boldsymbol{\Gamma}_{\mathrm{o}}$ are expressed as follows:

$$
\boldsymbol{\Phi}_{\mathrm{o}}=e^{-R_{\mathrm{o}} T_{\mathrm{s}} / L_{\mathrm{o}}}, \boldsymbol{\Gamma}_{\mathrm{o}}=\frac{1}{R_{\mathrm{o}}}\left(1-e^{-R_{\mathrm{o}} T_{\mathrm{s}} / L_{\mathrm{o}}}\right)
$$

The output voltages and input currents are obtained according to the MC model shown in Equations (7) and (8):

$$
\left[\begin{array}{l}
u_{\mathrm{o} \alpha}[k] \\
u_{\mathrm{o} \beta}[k]
\end{array}\right]=T_{\mathrm{MC} \alpha \beta}\left[\begin{array}{l}
u_{\mathrm{i} \alpha}[k] \\
u_{\mathrm{i} \beta}[k]
\end{array}\right]
$$

and

$$
\left[\begin{array}{c}
i_{\mathrm{i} \alpha}[k] \\
i_{\mathrm{i} \beta}[k]
\end{array}\right]=T_{\mathrm{MC} \alpha \beta}^{\mathrm{T}}\left[\begin{array}{c}
i_{\mathrm{o} \alpha}[k] \\
i_{\mathrm{o} \beta}[k]
\end{array}\right] .
$$

In practice, MPC is implemented in a digital signal controller. Because of the well-known one sampling period delay caused by the digital control, the delay compensation needs to be implemented in every sampling period. The delay compensation is based on the discrete model with one beat in advance, which can be obtained from Equations (10), (12), (14) and (15):

$$
\begin{gathered}
{\left[\begin{array}{c}
\boldsymbol{i}_{\mathrm{S}}[k+2] \\
\boldsymbol{u}_{\mathrm{i}}[k+2]
\end{array}\right]=\boldsymbol{\Phi}_{\mathrm{i}}\left[\begin{array}{c}
\boldsymbol{i}_{\mathrm{S}}[k+1] \\
\boldsymbol{u}_{\mathrm{i}}[k+1]
\end{array}\right]+\boldsymbol{\Gamma}_{\mathrm{i}}\left[\begin{array}{c}
\boldsymbol{u}_{\mathrm{s}}[k+1] \\
\boldsymbol{i}_{\mathrm{i}}[k+1]
\end{array}\right],} \\
\boldsymbol{i}_{\mathrm{o}}[k+2]=\boldsymbol{\Phi}_{\mathrm{o}} \boldsymbol{i}_{\mathrm{o}}[k+1]+\boldsymbol{\Gamma}_{\mathrm{o}} \boldsymbol{u}_{\mathrm{o}}[k+1], \\
{\left[\begin{array}{c}
u_{\mathrm{o} \alpha}[k+1] \\
u_{\mathrm{o} \beta}[k+1]
\end{array}\right]=\boldsymbol{T}_{\mathrm{MC} \alpha \beta}\left[\begin{array}{c}
u_{\mathrm{i} \alpha}[k+1] \\
u_{\mathrm{i} \beta}[k+1]
\end{array}\right],}
\end{gathered}
$$

and

$$
\left[\begin{array}{c}
i_{\mathrm{i} \alpha}[k+1] \\
i_{\mathrm{i} \beta}[k+1]
\end{array}\right]=T_{\mathrm{MC} \alpha \beta}^{\mathrm{T}}\left[\begin{array}{c}
i_{\mathrm{o} \alpha}[k+1] \\
i_{\mathrm{o} \beta}[k+1]
\end{array}\right] .
$$

The detailed procedure to implement the delay compensation is presented in the next section.

\subsection{Control Flowchart}

The control flowchart of the conventional MPC scheme in the $k$ th sampling period is shown in Figure 2. Because of the one sampling period delay caused by the digital control in practice, the optimal switching state obtained in the $k$ th sampling period is applied to the MC in the $(k+1)$ th sampling period, and thus is denoted as $S[k+1]$. This means that the switching state $S[k]$ applied to the MC in the $k$ th sampling period has been determined in the $(k-1)$ th sampling period. 


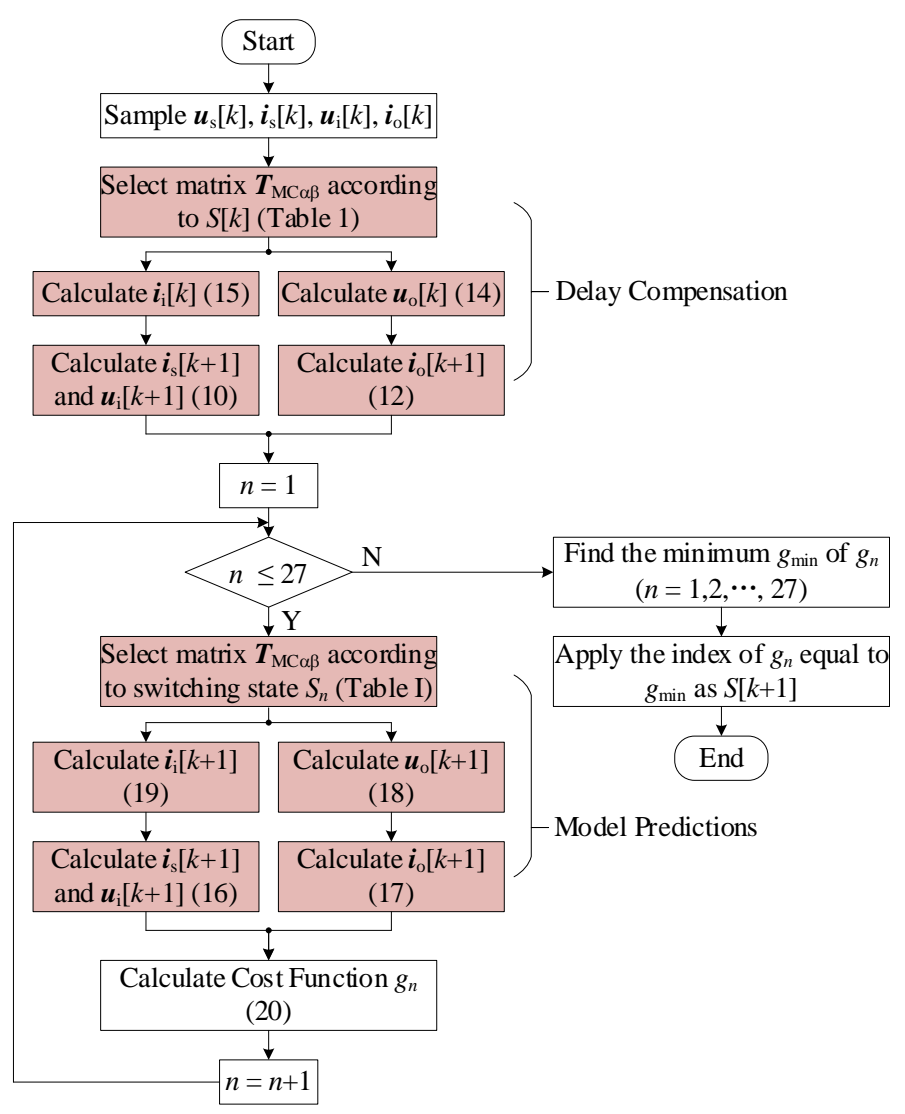

Figure 2. Control flowchart of the conventional MPC scheme.

According to Figure 2, the implementation of the conventional MPC in the $k$ th sampling period includes the following steps:

- Sample the source voltage $\boldsymbol{u}_{\mathrm{s}}[k]$, source current $i_{\mathrm{S}}[k]$, and output current $i_{\mathrm{o}}[k]$ at the beginning of the $k$ th sampling period. Analog-to-digital converter with high accuracy and small sampling delay is preferred at this step.

- Implement the delay compensation:

1. The present switching state $S[k]$ of the MC has been determined in the previous sampling period. The transformation matrix $T_{\mathrm{MC} \alpha \beta}$ corresponding to $S[k]$ can be obtained from Table 1.

2. The source current $i_{\mathrm{S}}[k+1]$, input voltage $\boldsymbol{u}_{\mathrm{i}}[k+1]$, and output current $i_{\mathrm{o}}[k+1]$ at the beginning of the $(k+1)$ th sampling period are calculated from Equations (10) and (12), respectively.

3. Calculate the output voltage $\boldsymbol{u}_{\mathrm{o}}[k]$ and input current $i_{\mathrm{i}}[k]$ according to the obtained $\boldsymbol{T}_{\mathrm{MC} \alpha \beta}$, which are based on Equations (14) and (15), respectively.

- Implement the model predictions and cost function calculation, which repeats the following steps 27 times:

1. Select the transfer matrix $\boldsymbol{T}_{\mathrm{MC} \alpha \beta}$ according to the $n$th switching state $S_{n}$ from Table 1 , where $n$ is the loop index.

2. Calculate the output voltage $\boldsymbol{u}_{\mathrm{o}}[k+1]$ and input current $\boldsymbol{i}_{\mathrm{o}}[k+1]$ based on Equations (18) and (19), respectively.

3. Predict the source current $i_{\mathrm{S}}[k+2]$, input voltage $\boldsymbol{u}_{\mathrm{i}}[k+1]$, and output current $i_{\mathrm{O}}[k+2]$ at the beginning of the $(k+2)$ th sampling period according to Equations (16) and (17), respectively. 
The source voltage $\boldsymbol{u}_{\mathrm{s}}[k+1]$ can be approximated by $\boldsymbol{u}_{\mathrm{s}}[k]$, or can be obtained with the Lagrange interpolation for higher accuracy [14].

4. Calculate the cost function $g_{n}$ corresponding to the switching state $S_{n}$. The cost function is the only criterion to determine the best switching state, which should include all the concerned control objectives. The differences among conventional MPC schemes mainly lie in the expressions of the cost function. In this paper, the cost function is defined as the weighted quadratic sum of the prediction errors of source and output currents:

$$
g=\lambda\left|i_{\mathrm{s}}^{*}-i_{\mathrm{s}}[k+2]\right|^{2}+\left|i_{\mathrm{o}}^{*}-i_{\mathrm{o}}[k+2]\right|^{2},
$$

where $\lambda$ is the weighting factor of the source current; superscript ${ }^{*}$ denotes the reference value. Details of this kind of MPC are presented in [11,14].

- Find the minimum value $g_{\min }$ of $g_{n}(n=1,2, \ldots, 27)$ and apply the index of $g_{\min }$ as $S[k+1]$.

One can conclude from the above steps that the conventional MPC scheme assumes input voltage $u_{\mathrm{i}}$ and output current $i_{\mathrm{O}}$ to be invariable in one sampling period. However, $\boldsymbol{u}_{\mathrm{i}}$ and $\boldsymbol{i}_{\mathrm{o}}$ are only imposed by the input filter capacitor $C_{\mathrm{f}}$ and output inductor $L_{\mathrm{o}}$, respectively. Consequently, the input side of the $\mathrm{MC}$ is not an ideal voltage source and the output side is not an ideal current source. If $C_{\mathrm{f}}$ and $L_{\mathrm{o}}$ are not large enough, interaction between input and output circuits will lead to variations of $\boldsymbol{u}_{\mathrm{i}}$ and $\boldsymbol{i}_{\mathrm{o}}$ in every sampling period, subject to which switching state is applied to the MC. This interaction inevitably causes increased prediction errors, especially when the sampling period is large, which increases the variations of $\boldsymbol{u}_{\mathrm{i}}$ and $\boldsymbol{i}_{\mathrm{o}}$. For MPC, larger prediction errors always introduce more harmonics.

\section{Improved MPC Based on the Precise Prediction Model}

\subsection{Precise Prediction Model for the MC System}

As discussed in Section 2, the conventional MPC discretizes the input and output circuit models separately, which ignores the input-output interaction and is the reason for the large prediction errors. To reduce the prediction errors, MPC for the MC is improved by adopting the precise prediction model.

Equations (2), (4), (7) and (8) represent the continuous models for the input circuit, output circuit, output voltages and input currents of the MC system, respectively. They can be rewritten into one integral state-space equation as follows:

$$
\frac{\mathrm{d}}{\mathrm{d} t}\left[\begin{array}{c}
i_{\mathrm{s} \alpha} \\
i_{\mathrm{s} \beta} \\
u_{\mathrm{i} \alpha} \\
u_{\mathrm{i} \beta} \\
i_{\mathrm{o} \alpha} \\
i_{\mathrm{o} \beta}
\end{array}\right]=A_{\mathrm{MC}}\left[\begin{array}{c}
i_{\mathrm{s} \alpha} \\
i_{\mathrm{s} \beta} \\
u_{\mathrm{i} \alpha} \\
u_{\mathrm{i} \beta} \\
i_{\mathrm{o} \alpha} \\
i_{\mathrm{o} \beta}
\end{array}\right]+\boldsymbol{B}_{\mathrm{MC}}\left[\begin{array}{c}
u_{\mathrm{s} \alpha} \\
u_{\mathrm{s} \beta}
\end{array}\right]
$$

where matrices $A_{\mathrm{MC}}$ and $\boldsymbol{B}_{\mathrm{MC}}$ are expressed as

$$
A_{\mathrm{MC}}=\left[\begin{array}{cccccc}
-R_{\mathrm{f}} / L_{\mathrm{f}} & 0 & -1 / L_{\mathrm{f}} & 0 & 0 & 0 \\
0 & -R_{\mathrm{f}} / L_{\mathrm{f}} & 0 & -1 / L_{\mathrm{f}} & 0 & 0 \\
1 / C_{\mathrm{f}} & 0 & 0 & 0 & T_{\alpha \alpha} / C_{\mathrm{f}} & T_{\beta \alpha} / C_{\mathrm{f}} \\
0 & 1 / C_{\mathrm{f}} & 0 & 0 & T_{\alpha \beta} / C_{\mathrm{f}} & T_{\beta \beta} / C_{\mathrm{f}} \\
0 & 0 & T_{\alpha \alpha} / L_{\mathrm{o}} & T_{\alpha \beta} / L_{\mathrm{o}} & -R_{\mathrm{o}} / L_{\mathrm{o}} & 0 \\
0 & 0 & T_{\beta \alpha} / L_{\mathrm{o}} & T_{\beta \beta} / L_{\mathrm{o}} & 0 & -R_{\mathrm{o}} / L_{\mathrm{o}}
\end{array}\right]
$$


and

$$
\boldsymbol{B}_{\mathrm{MC}}=\left[\begin{array}{cc}
1 / L_{\mathrm{f}} & 0 \\
0 & 1 / L_{\mathrm{f}} \\
0 & 0 \\
0 & 0 \\
0 & 0 \\
0 & 0
\end{array}\right]
$$

respectively.

In the continuous domain, Equation (21) is equivalent to the combination of Equations (2), (4), (7) and (8). Therefore, if the control strategy is implemented in the continuous domain, the control performance obtained with Equation (21) is exactly the same as that obtained with the combination of the separate continuous models. Nevertheless, the MPC scheme for the MC has to be implemented in a digital signal processor, which requires discrete control. As studied in [27], the discretization method has significant influence on the performance of a discrete controller. This is also true for MPC, as presented below.

The discretized equation of Equation (21) is as follows:

$$
\left[\begin{array}{c}
i_{\mathrm{s} \alpha}[k+1] \\
i_{\mathrm{s} \beta}[k+1] \\
u_{\mathrm{i} \alpha}[k+1] \\
u_{\mathrm{i} \beta}[k+1] \\
i_{\mathrm{o} \alpha}[k+1] \\
i_{\mathrm{o} \beta}[k+1]
\end{array}\right]=\boldsymbol{\Phi}_{\mathrm{P}}\left[\begin{array}{c}
i_{\mathrm{s} \alpha}[k] \\
i_{\mathrm{s} \beta}[k] \\
u_{\mathrm{i} \alpha}[k] \\
u_{\mathrm{i} \beta}[k] \\
i_{\mathrm{o} \alpha}[k] \\
i_{\mathrm{o} \beta}[k]
\end{array}\right]+\Gamma_{\mathrm{P}}\left[\begin{array}{c}
u_{\mathrm{s} \alpha}[k] \\
u_{\mathrm{s} \beta}[k]
\end{array}\right]
$$

where matrices $\boldsymbol{\Phi}_{\mathrm{P}}$ and $\boldsymbol{\Gamma}_{\mathrm{P}}$ are expressed as follows:

$$
\boldsymbol{\Phi}_{\mathrm{P}}=e^{A_{\mathrm{MC}} T_{\mathrm{s}}}, \boldsymbol{\Gamma}_{\mathrm{P}}=A_{\mathrm{MC}}^{-1}\left(\boldsymbol{\Phi}_{\mathrm{MC}}-\mathbf{I}_{6 \times 6}\right) \boldsymbol{B}_{\mathrm{MC}}
$$

Equation (24) is the precise prediction model for the improved MPC. It can be seen that the precise prediction model does not explicitly include the input currents and output voltages, but matrices in this model are dependent on the transfer matrix $\boldsymbol{T}_{\mathrm{MC} \alpha \beta}$ of the MC. According to Table 1, each switching state corresponds to a matrix $\boldsymbol{T}_{\mathrm{MC} \alpha \beta}$. Therefore, matrices $\boldsymbol{\Phi}_{\mathrm{P}}$ and $\boldsymbol{\Gamma}_{\mathrm{P}}$ shown in Equation (24) are not fixed but vary with the switching state applied to the MC. There are 27 sets of $\boldsymbol{\Phi}_{\mathrm{P}}$ and $\boldsymbol{\Gamma}_{\mathrm{P}}$ in total. According to discrete control theory, the precise prediction model includes the interaction between input and output circuits as much as possible. Therefore, it can accurately describe the MC's behavior during one sampling period, benefiting from the reduction of prediction errors for MPC.

Similar to the conventional MPC, the improved MPC with the precise prediction model must consider the one sampling period delay caused by the digital signal. The prediction model with one beat in advance is expressed as follows:

$$
\left[\begin{array}{c}
i_{\mathrm{s} \alpha}[k+2] \\
i_{\mathrm{s} \beta}[k+2] \\
u_{\mathrm{i} \alpha}[k+2] \\
u_{\mathrm{i} \beta}[k+2] \\
i_{\mathrm{o} \alpha}[k+2] \\
i_{\mathrm{o} \beta}[k+2]
\end{array}\right]=\boldsymbol{\Phi}_{\mathrm{P}}\left[\begin{array}{c}
i_{\mathrm{s} \alpha}[k+1] \\
i_{\mathrm{s} \beta}[k+1] \\
u_{\mathrm{i} \alpha}[k+1] \\
u_{\mathrm{i} \beta}[k+1] \\
i_{\mathrm{o} \alpha}[k+1] \\
i_{\mathrm{o} \beta}[k+1]
\end{array}\right]+\Gamma_{\mathrm{P}}\left[\begin{array}{l}
u_{\mathrm{s} \alpha}[k+1] \\
u_{\mathrm{s} \beta}[k+1]
\end{array}\right]
$$

\subsection{Eigenvalue Analysis}

It should be noted that, for the conventional MPC scheme, combining Equations (10), (12), (14), and (15) can also generate an integral system model. However, this prediction model has essential differences with the precise model obtained by the proposed approach, as discussed below. 
By substituting Equations (14) and (15) into (10) and (12), the integral system model for the conventional MPC scheme can be expressed as follows:

$$
\left[\begin{array}{c}
i_{\mathrm{s} \alpha}[k+1] \\
i_{\mathrm{s} \beta}[k+1] \\
u_{\mathrm{i} \alpha}[k+1] \\
u_{\mathrm{i} \beta}[k+1] \\
i_{\mathrm{o} \alpha}[k+1] \\
i_{\mathrm{o} \beta}[k+1]
\end{array}\right]=\boldsymbol{\Phi}_{\mathrm{C}}\left[\begin{array}{c}
i_{\mathrm{s} \alpha}[k] \\
i_{\mathrm{s} \beta}[k] \\
u_{\mathrm{i} \alpha}[k] \\
u_{\mathrm{i} \beta}[k] \\
i_{\mathrm{o} \alpha}[k] \\
i_{\mathrm{o} \beta}[k]
\end{array}\right]+\Gamma_{\mathrm{C}}\left[\begin{array}{c}
u_{\mathrm{s} \alpha}[k] \\
u_{\mathrm{s} \beta}[k]
\end{array}\right],
$$

where matrices $\boldsymbol{\Phi}_{C}$ and $\boldsymbol{\Gamma}_{C}$ are expressed as

$$
\boldsymbol{\Phi}_{\mathrm{C}}=\left[\begin{array}{cccccc}
\boldsymbol{\Phi}_{\mathrm{i}}(1,1) & 0 & \boldsymbol{\Phi}_{\mathrm{i}}(1,2) & 0 & \boldsymbol{\Gamma}_{\mathrm{i}}(1,2) T_{\mathrm{MC} \alpha \beta}(1,1) & \boldsymbol{\Gamma}_{\mathrm{i}}(1,2) T_{\mathrm{MC} \alpha \beta}(2,1) \\
0 & \boldsymbol{\Phi}_{\mathrm{i}}(1,1) & 0 & \boldsymbol{\Phi}_{\mathrm{i}}(1,2) & \boldsymbol{\Gamma}_{\mathrm{i}}(1,2) T_{\mathrm{MC} \alpha \beta}(1,2) & \boldsymbol{\Gamma}_{\mathrm{i}}(1,2) T_{\mathrm{MC} \alpha \beta}(2,2) \\
\boldsymbol{\Phi}_{\mathrm{i}}(2,1) & 0 & \boldsymbol{\Phi}_{\mathrm{i}}(2,2) & 0 & \boldsymbol{\Gamma}_{\mathrm{i}}(2,2) T_{\mathrm{MC} \alpha \beta}(1,1) & \boldsymbol{\Gamma}_{\mathrm{i}}(2,2) T_{\mathrm{MC} \beta \beta}(2,1) \\
0 & \boldsymbol{\Phi}_{\mathrm{i}}(2,1) & 0 & \boldsymbol{\Phi}_{\mathrm{i}}(2,2) & \boldsymbol{\Gamma}_{\mathrm{i}}(2,2) T_{\mathrm{MC} \alpha \beta}(1,2) & \boldsymbol{\Gamma}_{\mathrm{i}}(2,2) T_{\mathrm{MC} \beta}(2,2) \\
0 & 0 & \boldsymbol{\Gamma}_{\mathrm{o}} T_{\mathrm{MC} \alpha \beta}(1,1) & \boldsymbol{\Gamma}_{\mathrm{o}} T_{\mathrm{MC} \alpha \beta}(1,2) & \boldsymbol{\Phi}_{\mathrm{o}} & 0 \\
0 & 0 & \boldsymbol{\Gamma}_{\mathrm{o}} T_{\mathrm{MC} \alpha \beta}(2,1) & \boldsymbol{\Gamma}_{\mathrm{o}} T_{\mathrm{MC} \alpha \beta}(2,2) & 0 & \boldsymbol{\Phi}_{\mathrm{o}}
\end{array}\right]
$$

and

$$
\Gamma_{C}=\left[\begin{array}{cc}
\Gamma_{\mathrm{i}}(1,1) & 0 \\
0 & \Gamma_{\mathrm{i}}(1,1) \\
\Gamma_{\mathrm{i}}(2,1) & 0 \\
0 & \Gamma_{\mathrm{i}}(2,1) \\
0 & 0 \\
0 & 0
\end{array}\right]
$$

Clearly, matrices $\boldsymbol{\Phi}_{C}$ and $\boldsymbol{\Gamma}_{C}$ are quite different from matrices $\boldsymbol{\Phi}_{\mathrm{P}}$ and $\boldsymbol{\Gamma}_{\mathrm{P}}$.

According to control theory, eigenvalues can be used to characterize the behavior of a system. Eigenvalues of the discrete prediction model should be equal to those transformed from the continuous model, so as to accurately describe the MC's behavior with MPC in the discrete domain. As the dimensions of $A_{\mathrm{MC}}, \boldsymbol{\Phi}_{\mathrm{P}}$, and $\boldsymbol{\Phi}_{\mathrm{C}}$ are all $6 \times 6$, there are six eigenvalues for each matrix. Assuming that the first switching state shown in Table 1 is applied to the MC, the six eigenvalues of $A_{\mathrm{MC}}, \boldsymbol{\Phi}_{\mathrm{P}}$, and $\boldsymbol{\Phi}_{C}$ are listed in Table 2. To better show the differences, the eigenvalues of the continuous matrix $A_{\mathrm{MC}}$ are transformed into the discrete domain. It is clear that all the eigenvalues generated by the improved MPC are always the same as those transformed from the continuous model, no matter what the sampling time $T_{\mathrm{s}}$. On the contrary, two eigenvalues generated by the conventional MPC scheme are quite different from the expected. The larger the sampling time or, equivalently, the smaller the filter components, the more significant is the difference.

Figure 3 shows how the conventional and improved MPC schemes differ from each other in the aspect of prediction performance. Parameters used in this case are the same as those adopted in the experimental verification. One can conclude that the improved MPC can exactly predict the input voltage and output current at the end of every sampling period, whereas prediction errors are always generated by the conventional MPC. This is the result of the prediction models with different accuracy. 
Table 2. Eigenvalues of matrices $A_{\mathrm{MC}}, \boldsymbol{\Phi}_{\mathrm{P}}$, and $\boldsymbol{\Phi}_{\mathrm{C}}$.

\begin{tabular}{cccc}
\hline \multirow{2}{*}{ Sampling Time $\boldsymbol{T}_{\mathbf{S}}$} & Continuous Model & Proposed Model & Conventional Model \\
\cline { 2 - 4 } & $\boldsymbol{e}^{\boldsymbol{\lambda}_{A_{\mathrm{MC}} \boldsymbol{T}_{\mathbf{S}}}}$ & $\lambda_{\boldsymbol{\Phi}_{\mathbf{P}}}$ & $\lambda_{\boldsymbol{\Phi}_{\mathbf{C}}}$ \\
\hline 0.9587 & 0.9587 & 0.9587 \\
\multirow{2}{*}{$20 \mu \mathrm{s}$} & 0.9674 & 0.9674 & 0.9676 \\
& $0.9676-0.2338 \mathrm{i}$ & $0.9676-0.2338 \mathrm{i}$ & $0.9735-0.2354 \mathrm{i}$ \\
& $0.9676+0.2338 \mathrm{i}$ & $0.9676+0.2338 \mathrm{i}$ & $0.9735+0.2354 \mathrm{i}$ \\
& $0.9779-0.2087 \mathrm{i}$ & $0.9779-0.2087 \mathrm{i}$ & $0.9779-0.2087 \mathrm{i}$ \\
& $0.9779-0.2087 \mathrm{i}$ & $0.9779-0.2087 \mathrm{i}$ & $0.9779-0.2087 \mathrm{i}$ \\
$40 \mu \mathrm{s}$ & 0.9192 & 0.9192 & 0.9192 \\
& 0.9358 & 0.9358 & 0.9365 \\
& $0.8816-0.4524 \mathrm{i}$ & $0.8816-0.4524 \mathrm{i}$ & $0.9040-0.4612 \mathrm{i}$ \\
& $0.8816+0.4524 \mathrm{i}$ & $0.8816+0.4524 \mathrm{i}$ & $0.9040+0.4612 \mathrm{i}$ \\
& $0.9127-0.4082 \mathrm{i}$ & $0.9127-0.4082 \mathrm{i}$ & $0.9127-0.4082 \mathrm{i}$ \\
& $0.9127+0.4082 \mathrm{i}$ & $0.9127+0.4082 \mathrm{i}$ & $0.9127+0.4082 \mathrm{i}$ \\
\hline
\end{tabular}

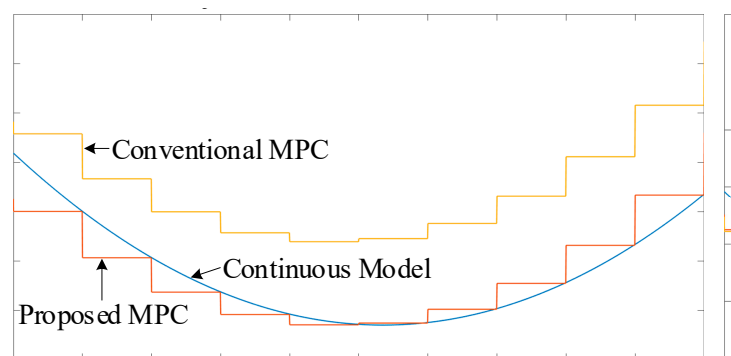

(a)

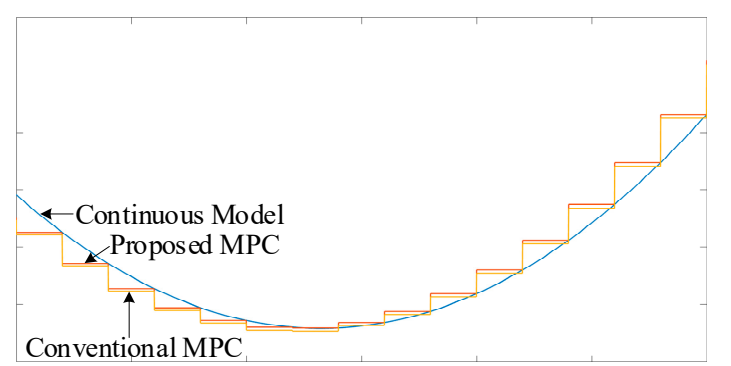

(b)

Figure 3. Prediction performance with the conventional and improved model predictive control (MPC) schemes: (a) the $\alpha$-axis input voltage $u_{\mathrm{i} \alpha} ;(\mathbf{b})$ the $\alpha$-axis output current $i_{\mathrm{o} \alpha}$.

\subsection{Control Flowchart}

The control flowchart of the improved MPC with the precise prediction model is shown in Figure 4. It can be seen from Figure 4 that the improved MPC obtains matrices $\boldsymbol{\Phi}_{\mathrm{P}}$ and $\boldsymbol{\Gamma}_{\mathrm{P}}$ corresponding to each valid switching state, instead of calculating the output voltage $\boldsymbol{u}_{\mathrm{O}}$ and input current $\boldsymbol{i}_{\mathrm{O}}$. As there are 27 sets of $\boldsymbol{\Phi}_{\mathrm{P}}$ and $\boldsymbol{\Gamma}_{\mathrm{P}}$, it is impractical to obtain $\boldsymbol{\Phi}_{\mathrm{P}}$ and $\boldsymbol{\Gamma}_{\mathrm{P}}$ online based on Equation (25). Fortunately, $\boldsymbol{\Phi}_{\mathrm{P}}$ and $\boldsymbol{\Gamma}_{\mathrm{P}}$ are fixed for each valid switching state under certain system parameters. Therefore, the 27 sets of $\boldsymbol{\Phi}_{\mathrm{P}}$ and $\boldsymbol{\Gamma}_{\mathrm{P}}$ can be calculated offline and stored in look-up tables. The digital signal controller only needs to look up each set of $\boldsymbol{\Phi}_{\mathrm{P}}$ and $\boldsymbol{\Gamma}_{\mathrm{P}}$ using the candidate switching state. Cost function calculation and its minimization in the improved MPC are exactly the same as in the conventional MPC.

As discussed in Section 3.2, the essential difference between the conventional and proposed MPC schemes lies in the eigenvalues of the prediction models. In addition, there are other differences between the two MPC schemes, which can be found by comparing the control flowcharts as presented below.

- As the discrete prediction models are quite different in the two MPC schemes, the procedure of the delay compensation and model predictions are also different. For the conventional MPC schemes, the input currents and output voltages are obtained first, and then the source and output currents are calculated using separate prediction models. On the contrary, the improved MPC scheme directly obtains the source and output currents using the integral prediction model.

- For the conventional MPC, each valid switching state corresponds to a set of input currents and output voltages, while the coefficients of the prediction models are fixed. On the contrary, the coefficients of the precise prediction model in the improved MPC vary with the switching state, while the input currents and output voltages are not explicitly used in the model prediction. The minimization procedure of the improved MPC is actually looking for the prediction model that generates the minimum cost function. 


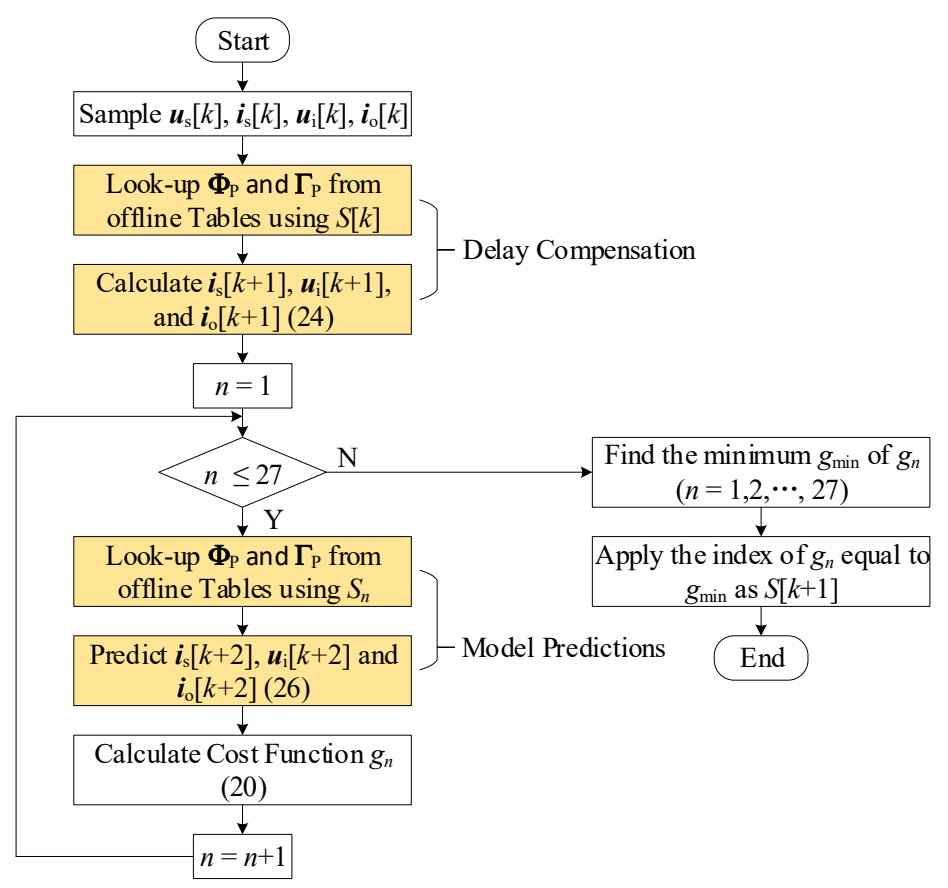

Figure 4. Control flowchart of the improved MPC with the precise prediction model.

\section{Experimental Verification}

Both the conventional and the improved MPC schemes are evaluated by experimental results. A picture of the experimental prototype is shown in Figure 5. The normal parameters of the prototype are listed in Table 3. Filter components are selected so that the converter can achieve satisfactory power quality when the sampling time is $20 \mu \mathrm{s}$. Values of the filter components are obtained with a high-accuracy LCR meter. The digital controller consists of a digital signal processor (DSP) TMS320F28379 and an FPGA (Field Programmable Gate Array). The DSP has dual CPU cores working at $200 \mathrm{MHz}$, which provides strong computational capability and enables the completion of all the calculations within $20 \mu \mathrm{s}$. The adopted weighting factor is obtained based on the experimental results under various values of it, so that the input and output power quality are optimal. One can conclude that the two MPC schemes have almost the same optimal weighing factor as the one listed in Table 3. Therefore, the same optimal weighting factors was selected for the two MPC schemes, which guarantees a fair comparison.

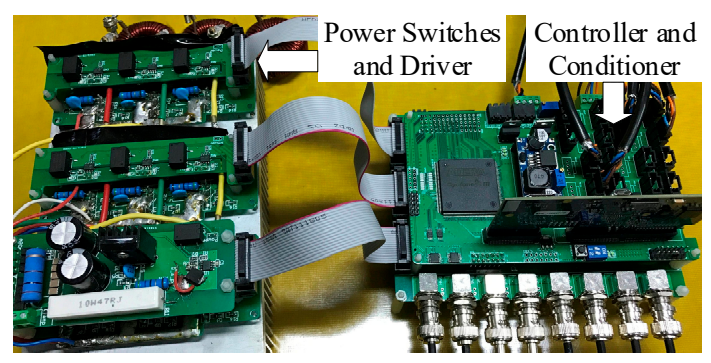

Figure 5. Picture of the experimental prototype. 
Table 3. Normal experimental parameters.

\begin{tabular}{ccc}
\hline Variables & Description & Values \\
\hline$U_{\mathrm{s}}$ & Source Voltage (L-L RMS) & $150 \mathrm{~V}$ \\
$f_{\mathrm{s}}$ & Source Frequency & $50 \mathrm{~Hz}$ \\
$i_{\mathrm{om}}{ }^{*}$ & Reference Amplitude of & $10 \mathrm{~A}$ \\
$f_{\mathrm{o}}$ & Output Current & $80 \mathrm{~Hz}$ \\
$L_{\mathrm{f}}$ & Output Frequency & $1.02 \mathrm{mH}$ \\
$C_{\mathrm{f}}$ & Input Filter Inductor & $8.87 \mu \mathrm{F}$ \\
$R_{\mathrm{f}}$ & Input Filter Capacitor & $0.05 \Omega$ \\
$L_{\mathrm{O}}$ & Resistance of $L_{\mathrm{f}}$ & $4.89 \mathrm{mH}$ \\
$R_{\mathrm{O}}$ & Output Inductor & $10.3 \Omega$ \\
$T_{\mathrm{s}}$ & Output Resistor & $20 \mu \mathrm{s}$ \\
$\lambda_{\mathrm{c}}$ & Sampling Time & 1.65 \\
\hline
\end{tabular}

The performances of the MC using the conventional and improved MPC schemes were comparatively evaluated under six cases. Experimental conditions of the six cases are summarized in Table 4. Case 1 evaluates the performance when all working conditions are normal as listed in Table 3. In Case 2, the sampling time is increased from $20 \mu \mathrm{s}$ to $40 \mu \mathrm{s}$. In Case 3, the parameters used in the calculation of the prediction model's coefficients are artificially increased or decreased by $5 \%$. In Case 4 , the output filter inductance $L_{\mathrm{o}}$ is reduced to $2.51 \mathrm{mH}$. In Case 5, source voltages are abnormal and contain $5 \%$ unbalanced component and 5\% 5th harmonic. In Case 6, the output current amplitude steps between $10 \mathrm{~A}$ and $5 \mathrm{~A}$ to evaluate the dynamic performance. The analysis results of the total harmonic distortions (THDs) of source and output currents at the steady state are listed in Table 5. Table 6 shows the execution time of the two MPC schemes. It can be seen that the improved MPC scheme consumes slightly more time to complete all the calculations. This is because all the elements in the matrices $\boldsymbol{\Phi}_{\mathrm{P}}$ and $\boldsymbol{\Gamma}_{\mathrm{P}}$ are nonzero for the improved MPC. For the conventional MPC, some elements in matrices $\boldsymbol{\Phi}_{\mathrm{C}}$ and $\boldsymbol{\Gamma}_{\mathrm{C}}$ are zero, which helps to simplify the control algorithm. Considering the reduction of the prediction errors as presented below, such a slight increase in the execution time is worthwhile.

Table 4. Experimental conditions.

\begin{tabular}{ccl}
\hline Case No. & State & \multicolumn{1}{c}{ Conditions } \\
\hline 1 & Steady & Normal Source Voltages, $T_{\mathrm{s}}=20 \mu \mathrm{s}$, Normal Parameters \\
2 & Steady & Normal Source Voltages, $T_{\mathrm{s}}=40 \mu \mathrm{s}$, Normal Parameters \\
3 & Steady & Normal Source Voltages, $T_{\mathrm{s}}=20 \mu \mathrm{s}$, Parameters with $5 \%$ Errors \\
4 & Steady & Normal Source Voltages, $T_{\mathrm{s}}=20 \mu \mathrm{s}, L_{\mathrm{o}}$ is Changed to $2.51 \mathrm{mH}$ \\
5 & Steady & Abnormal Source Voltages, $T_{\mathrm{s}}=20 \mu \mathrm{s}$, Normal Parameters \\
6 & Dynamic & Normal Source Voltages, $T_{\mathrm{s}}=20 \mu \mathrm{s}$, Normal Parameters \\
\hline
\end{tabular}

Table 5. Total harmonic distortions (THDs) of source and output currents at steady state.

\begin{tabular}{cccrc}
\hline \multirow{2}{*}{ Case No. } & \multicolumn{2}{c}{ Conventional MPC } & \multicolumn{2}{c}{ Improved MPC } \\
& THD of $\boldsymbol{i}_{\text {sA }}$ & THD of $\boldsymbol{i}_{\text {oU }}$ & THD of $\boldsymbol{i}_{\text {sA }}$ & THD of $\boldsymbol{i}_{\text {oU }}$ \\
\hline 1 & $4.61 \%$ & $2.07 \%$ & $3.47 \% \downarrow$ & $1.80 \% \downarrow$ \\
2 & $11.88 \%$ & $5.66 \%$ & $10.98 \% \downarrow$ & $4.72 \% \downarrow$ \\
3 & $5.32 \%$ & $2.08 \%$ & $3.95 \% \downarrow$ & $1.83 \% \downarrow$ \\
4 & $4.73 \%$ & $3.56 \%$ & $3.80 \% \downarrow$ & $3.14 \% \downarrow$ \\
5 & $9.04 \%$ & $2.10 \%$ & $7.65 \% \downarrow$ & $2.01 \% \downarrow$ \\
\hline
\end{tabular}


Table 6. Execution time.

\begin{tabular}{cc}
\hline Conventional MPC & Improved MPC \\
\hline $18.1 \mu \mathrm{s}$ & $19.3 \mu \mathrm{s}$ \\
\hline
\end{tabular}

The experimental results of Case 1 are shown in Figure 6. The prediction errors, which are the subtractions of the actual variables and the predicted ones, are denoted by the symbol $\Delta$. It can be seen that the improved MPC generates smaller prediction errors than the conventional MPC, especially the errors of input voltage $u_{\mathrm{iA}}$ and output current $i_{\mathrm{oU}}$. Benefiting from the reduction of prediction errors, the improved MPC has reduced the THDs of the source current $i_{\mathrm{sA}}$ and output current $i_{\mathrm{oU}}$ from $4.61 \%$ and $2.07 \%$ to $3.47 \%$ and $1.80 \%$, respectively, indicating that a better power quality is obtained.
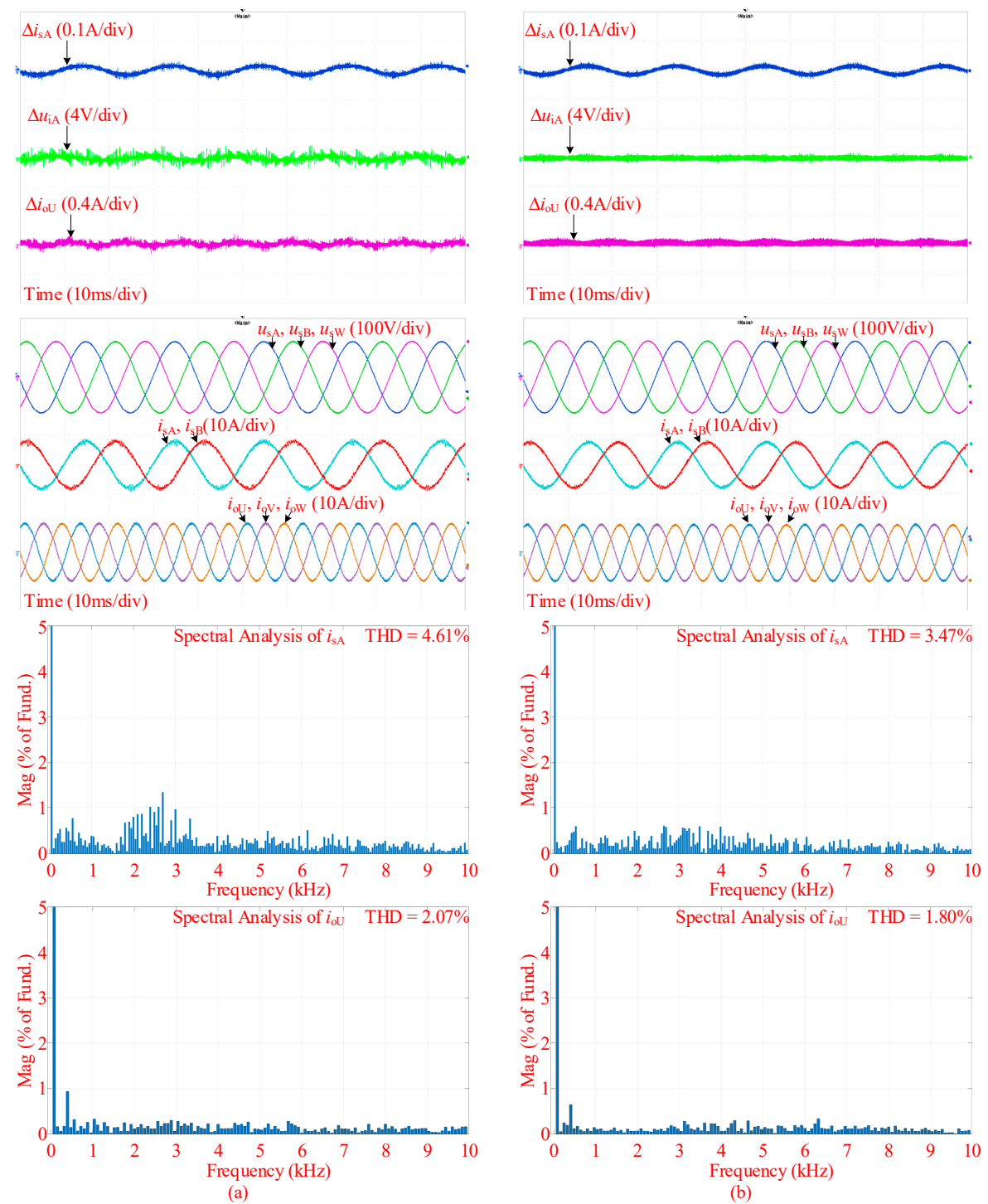

Figure 6. Experimental results of Case 1: (a) with the conventional MPC and (b) with the improved MPC. Experimental conditions are normal.

The experimental results of Case 2 are shown in Figure 7. One can conclude that, with the increase in sampling time, the conventional MPC generates significant prediction errors. On the contrary, the improved MPC still achieves much smaller prediction errors. With the improved MPC, THDs of $i_{\mathrm{SA}}$ and $i_{\mathrm{oU}}$ are reduced from $11.88 \%$ and $5.66 \%$ to $10.98 \%$ and $4.72 \%$, respectively. Differences of the 
spectral distribution between the two MPC schemes are more significant. It shows that the improved MPC helps to reduce harmonics at almost all frequency bands. The results prove that the improved MPC scheme is more effective under a larger sampling frequency.
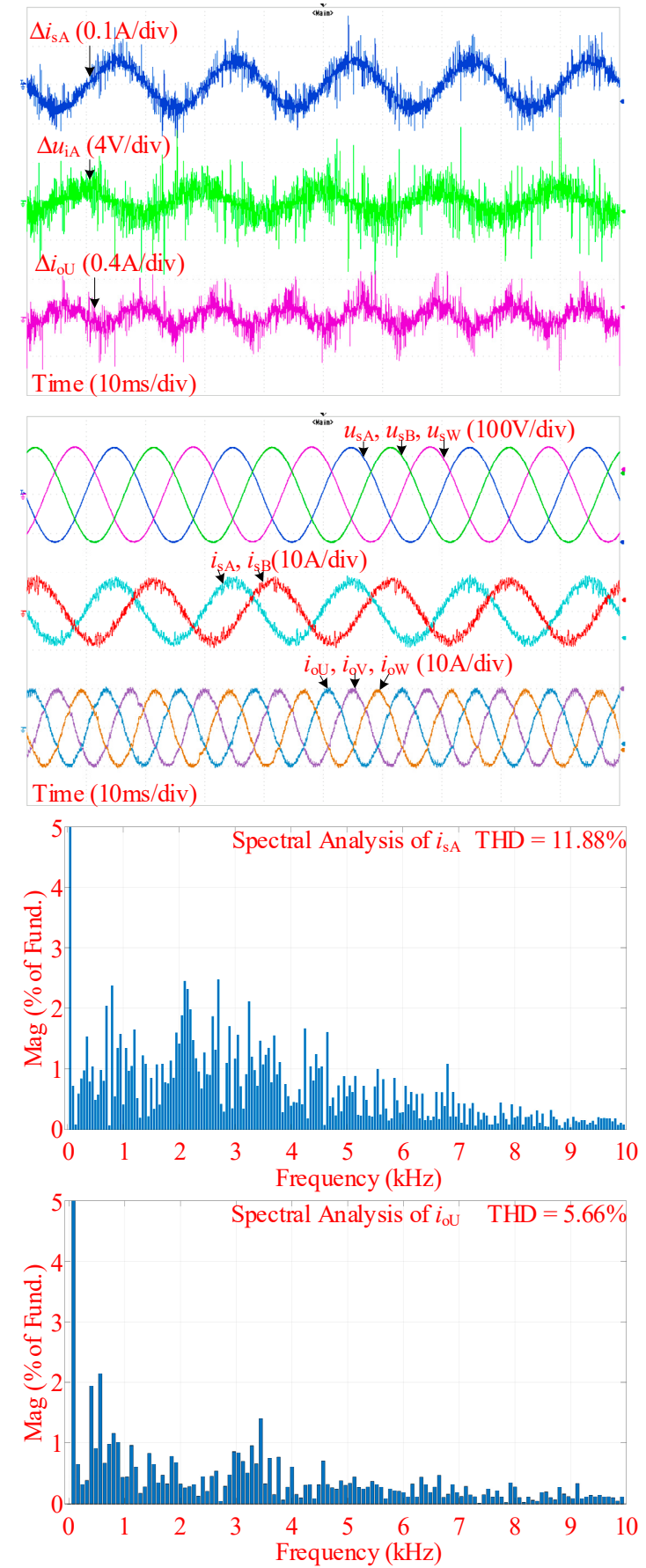

(a)

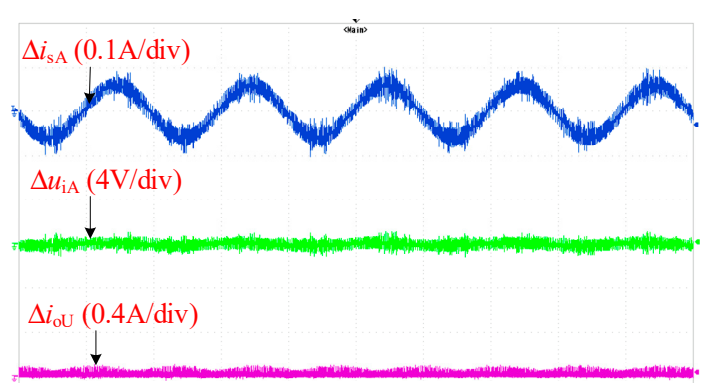

Time $(10 \mathrm{~ms} /$ div $)$
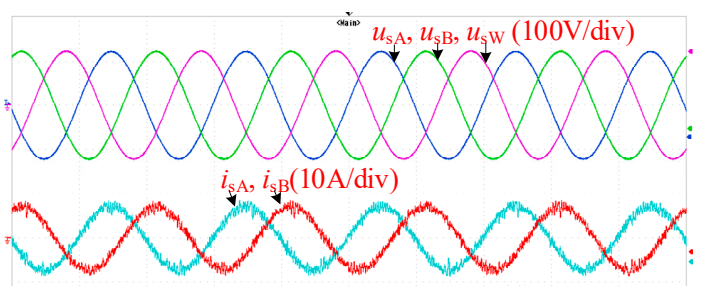
$i_{\mathrm{oU}}, i_{\mathrm{gV}}, i_{\mathrm{oW}}(10 \mathrm{~A} / \mathrm{div})$

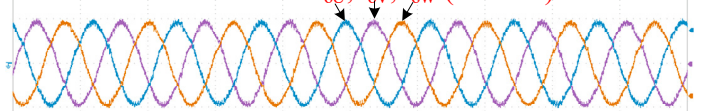

Time $(10 \mathrm{~ms} / \mathrm{div})$
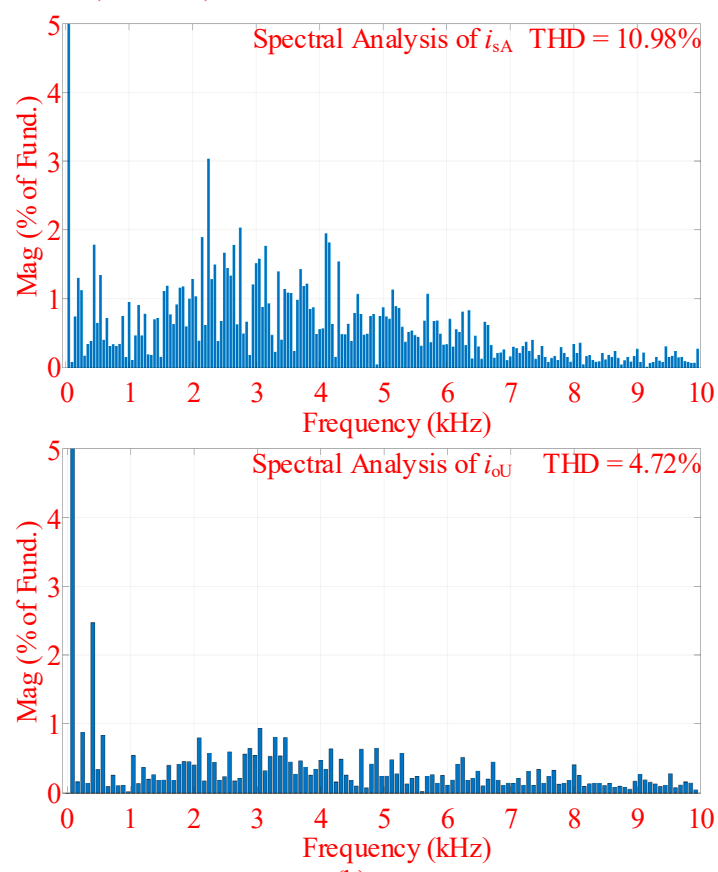

(b)

Figure 7. Experimental results of Case 2: (a) with the conventional MPC and (b) with the improved MPC. The sampling time is increased to $40 \mu \mathrm{s}$.

The experimental results of Case 3 are shown in Figure 8. It can be seen that the prediction errors of the two MPC schemes are increased when the parameters used in the prediction models are inaccurate, which also demonstrates the importance of the prediction model's accuracy. Even under such parameter variations, the improved MPC still achieves smaller prediction errors and a better 
waveform quality, with the THDs of source and output currents reduced from $5.32 \%$ and $2.08 \%$ to $3.95 \%$ and $1.83 \%$, respectively. Therefore, the improved MPC scheme has robustness with respect to the parameter variations.
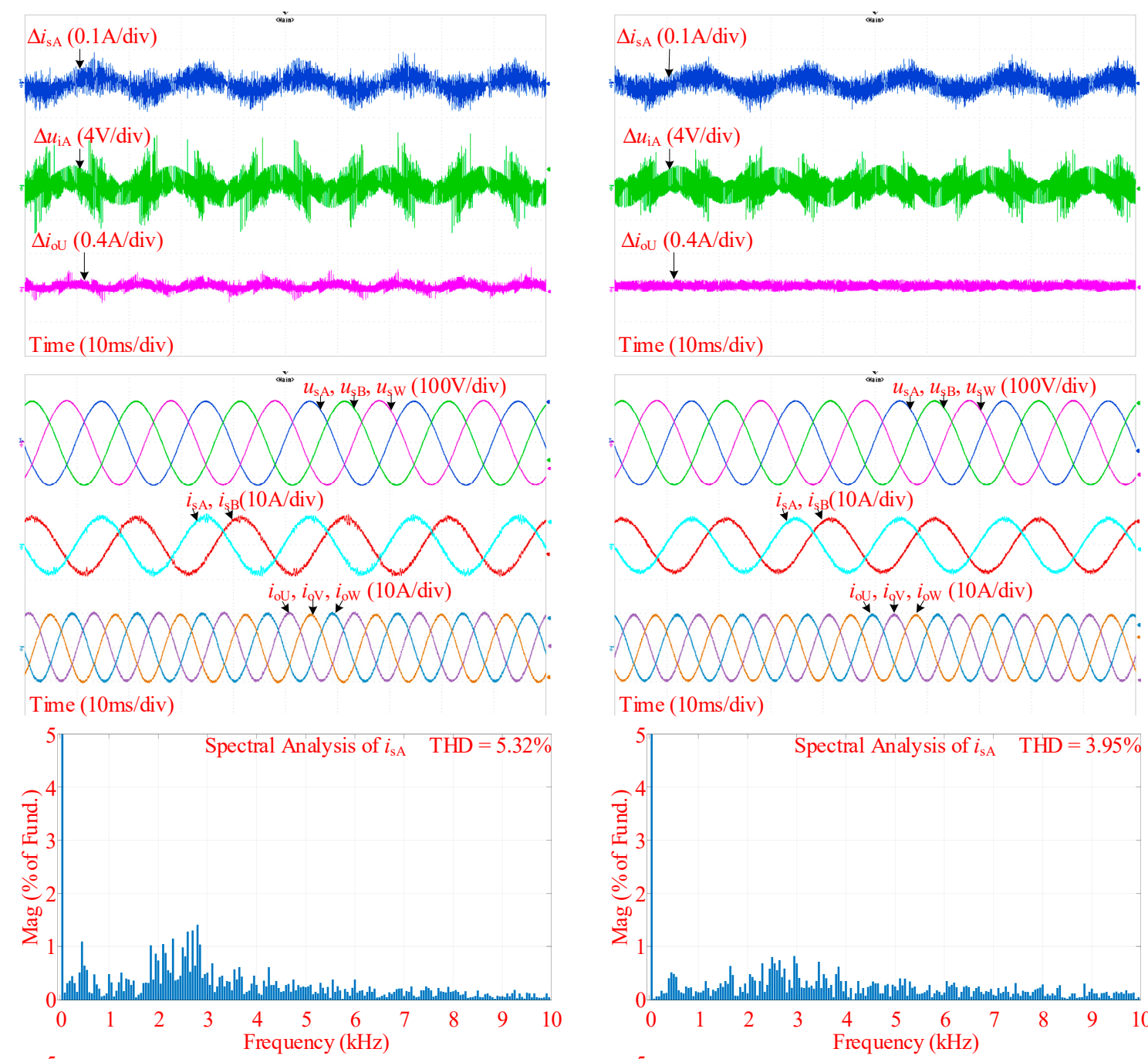

Time $(10 \mathrm{~ms} / \mathrm{div})$
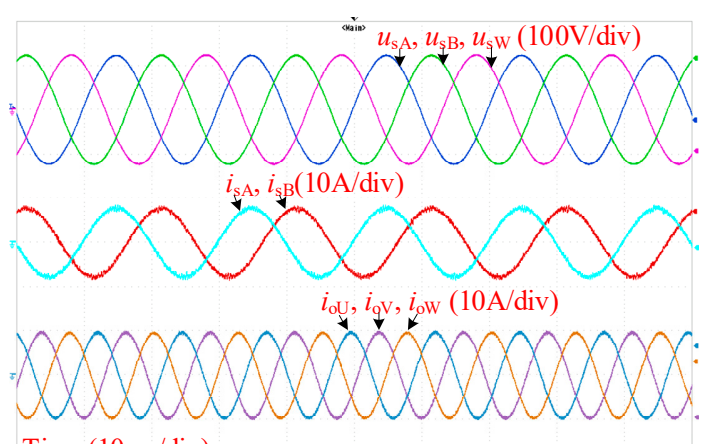

Time (10ms/div)
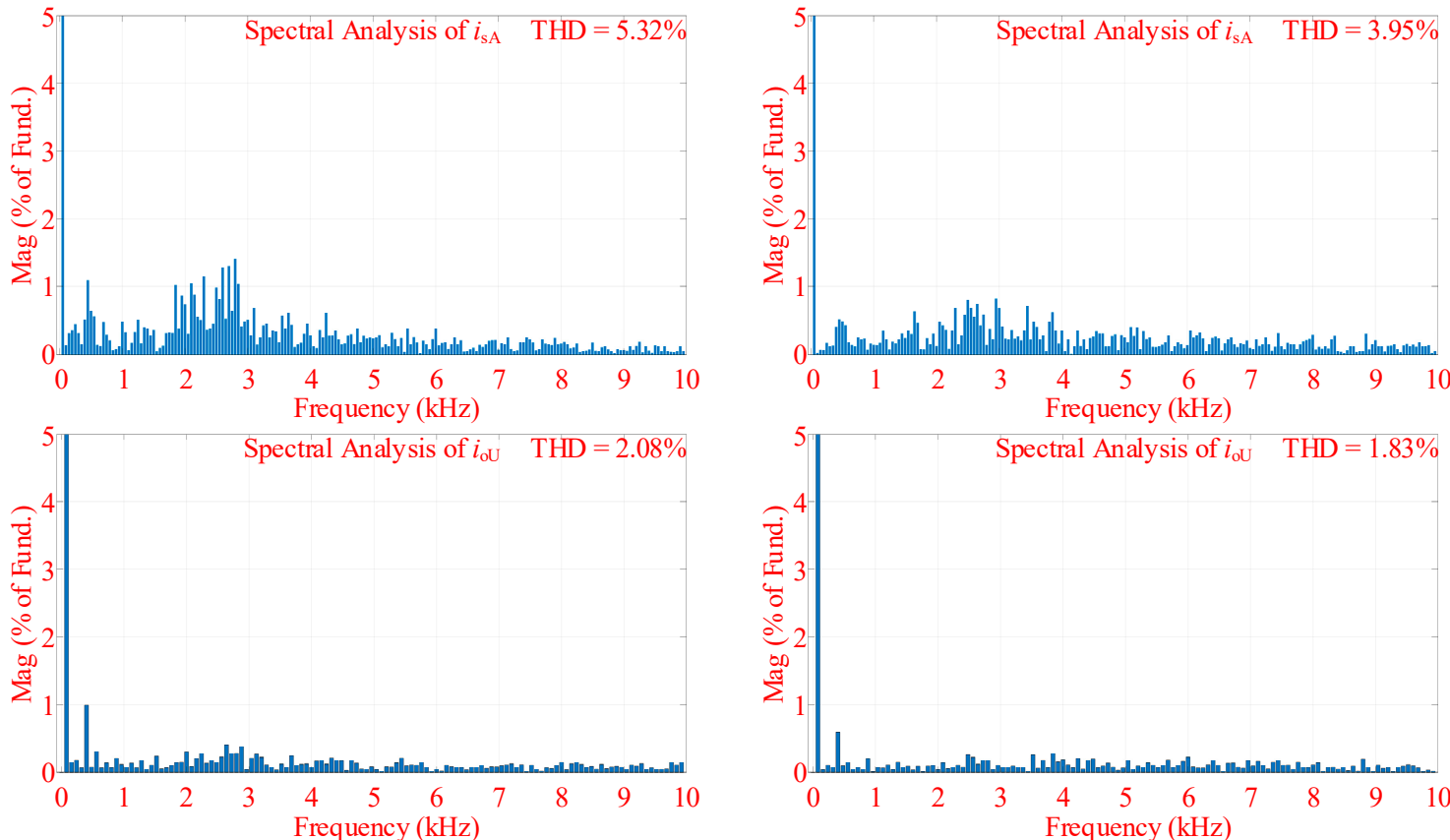

(a)

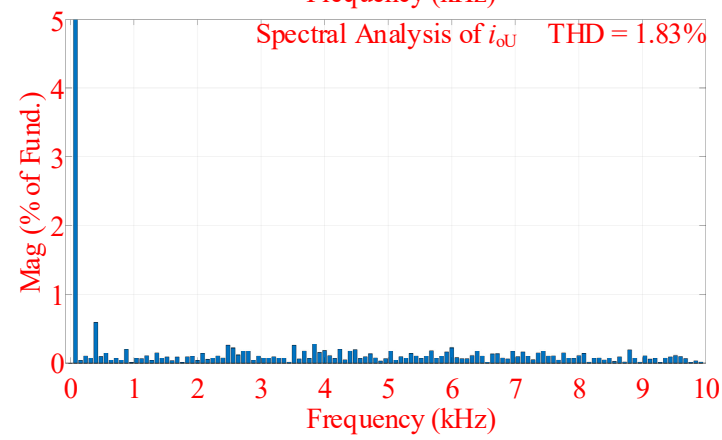

(b)

Figure 8. Experimental results of Case 3: (a) with the conventional MPC and (b) with the improved MPC. Parameters of the prediction models are inaccurate.

The experimental results of Case 4 are shown in Figure 9. It can be seen that when smaller output filter inductors are adopted, the prediction errors of both the conventional and improved MPC scheme are increased compared with those shown in Case 1. However, the improved MPC scheme still achieves 
significantly lower errors in this case. The THDs of the source and output currents are still lower than those of the conventional MPC scheme.
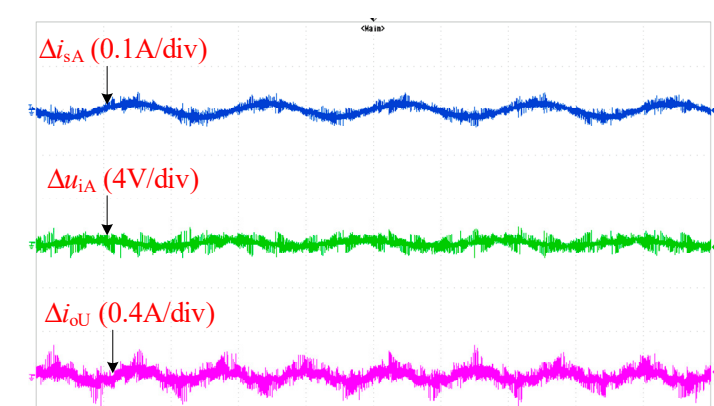

Time (10ms/div)
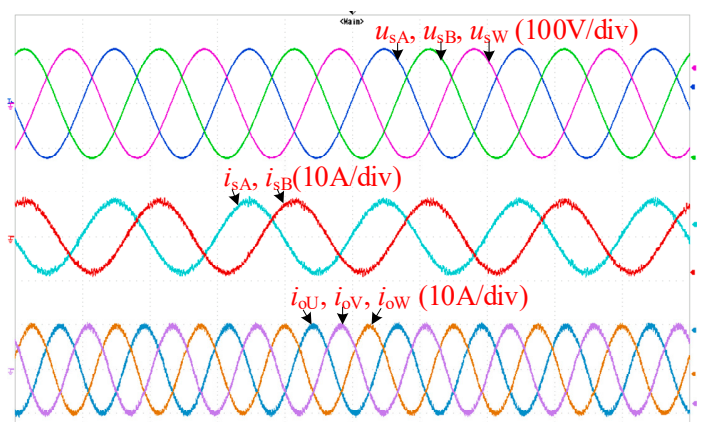

Time (10ms/div)
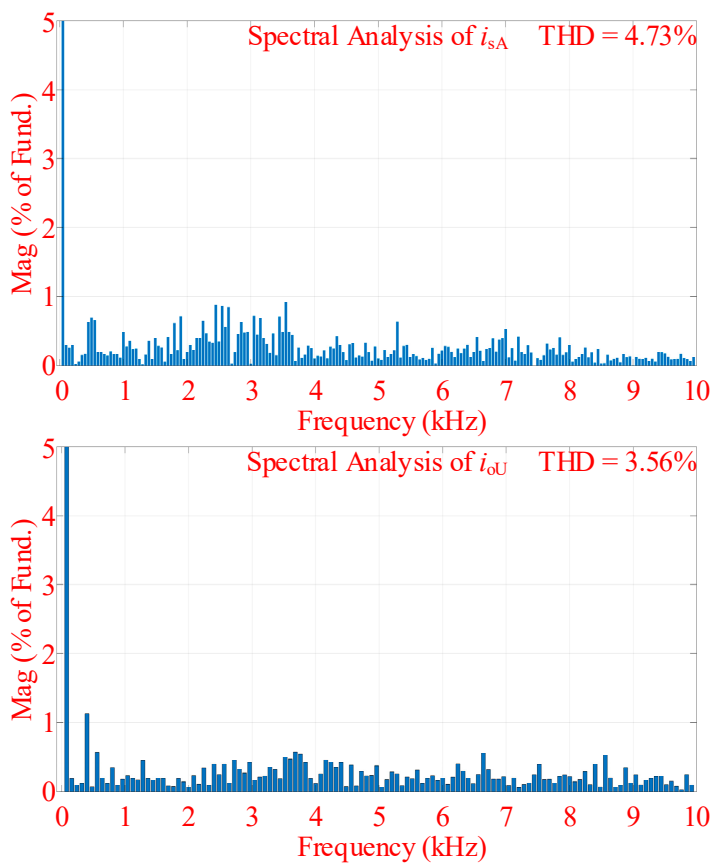

(a)
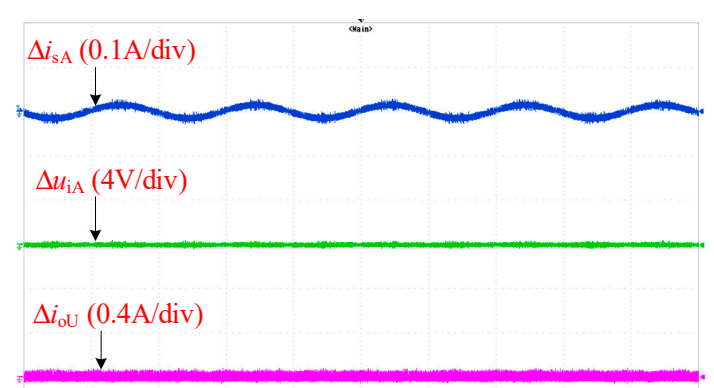

Time (10ms/div)
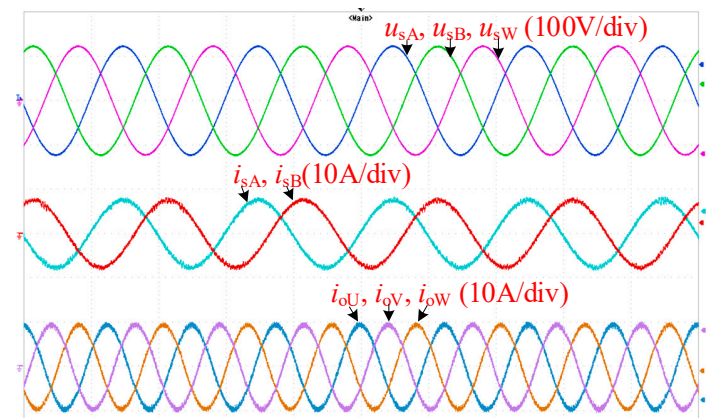

Time (10ms/div)
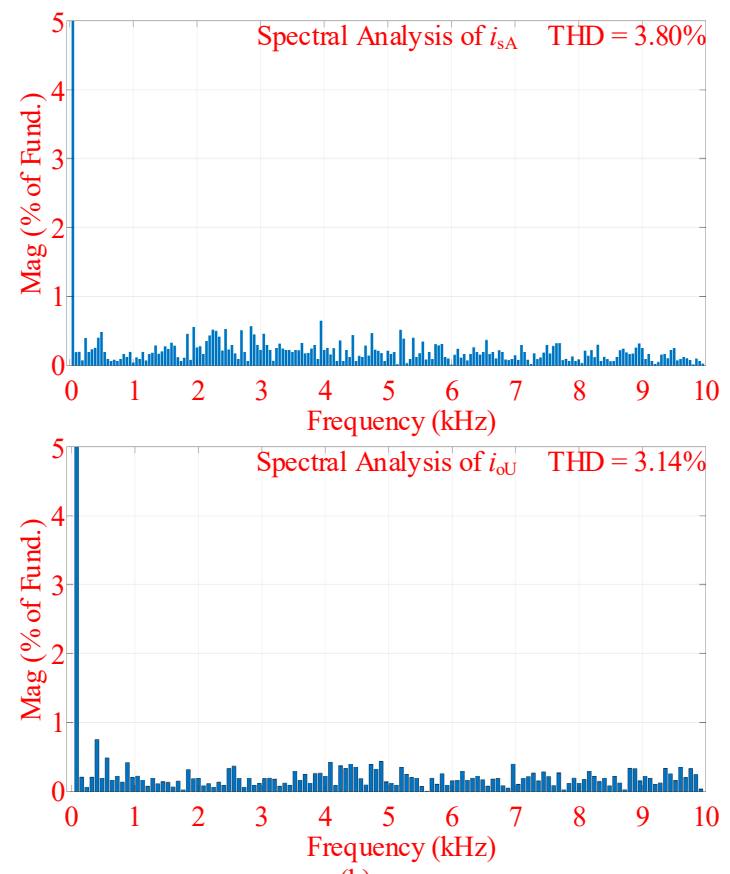

(b)

Figure 9. Experimental results of Case 4: (a) with the conventional MPC and (b) with the improved MPC. Output filter inductor is changed to $2.51 \mathrm{mH}$.

The experimental results of Case 5 are shown in Figure 10. It is clear that under unbalanced and distorted source voltages, prediction errors can still be reduced by the improved MPC, even though more low-order harmonics are contained in the source and output currents. With the improved MPC, a higher power quality is obtained. In particular, the THD of $i_{\mathrm{SA}}$ is reduced from $9.04 \%$ to $7.65 \%$. 
The experimental results of Case 6 are shown in Figure 11, where the reference amplitude of the output current steps between 10A and 5A. It shows that both the conventional and improved MPC schemes track the reference very fast. Therefore, the improved MPC scheme does not degrade the dynamic performance. It should be noted that the small differences of the reference current come from the different step moment and are not related to the MPC schemes.

In summary, the improved MPC based on the precise prediction model can always obtain a better power quality than the conventional MPC without degrading the dynamic control performance, no matter what the operation condition.
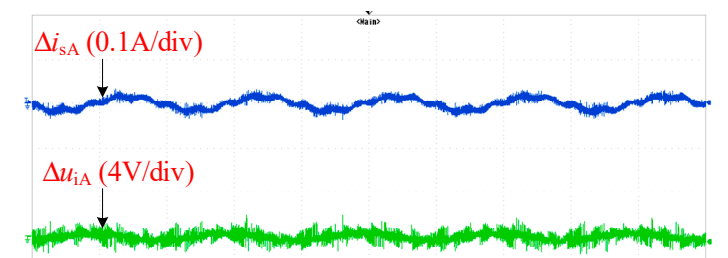

$\Delta i_{\mathrm{oU}}(0.4 \mathrm{~A} / \mathrm{div})$

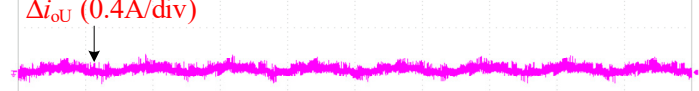

Time (10ms/div)
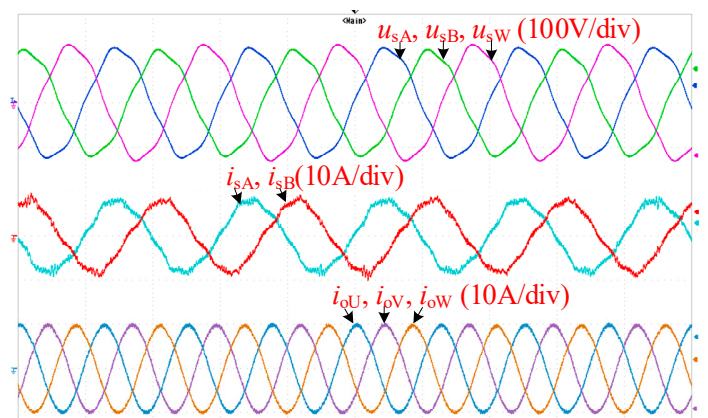

Time (10ms/div)
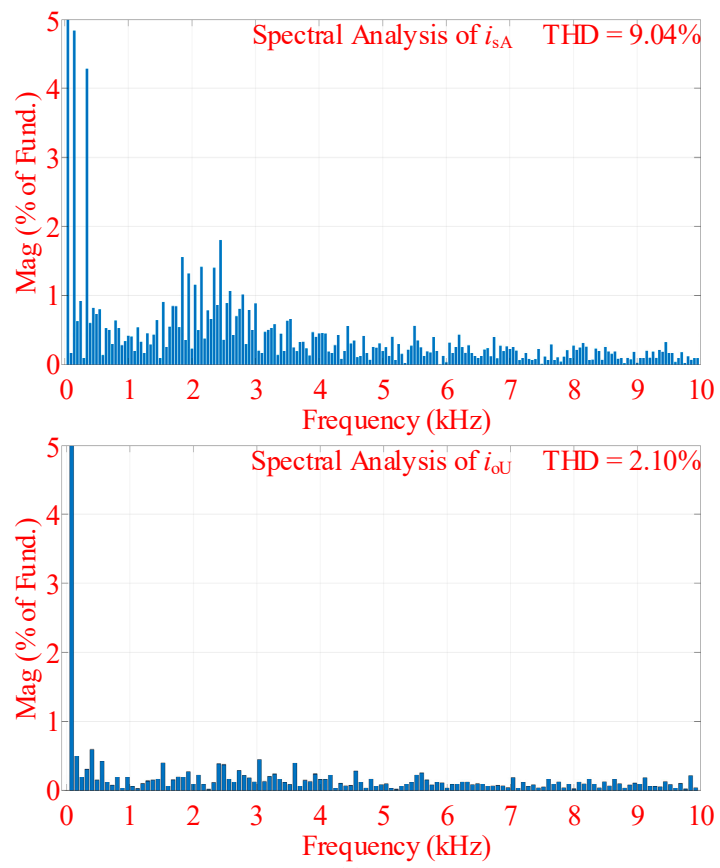

(a)
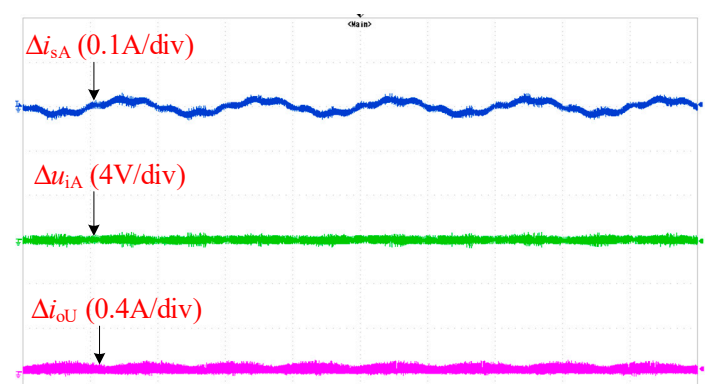

Time (10ms/div)
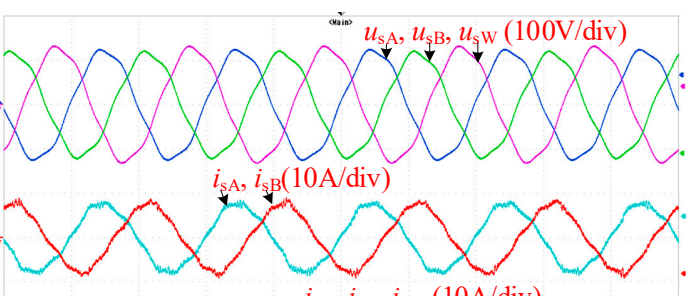
$i_{\mathrm{oU}}, i_{\mathrm{gV}}, i_{\mathrm{oW}}(10 \mathrm{~A} / \mathrm{div})$

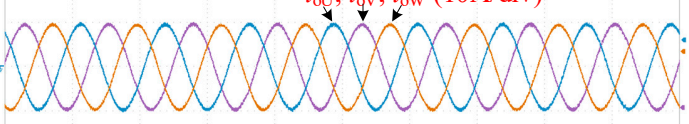

Time (10ms/div)
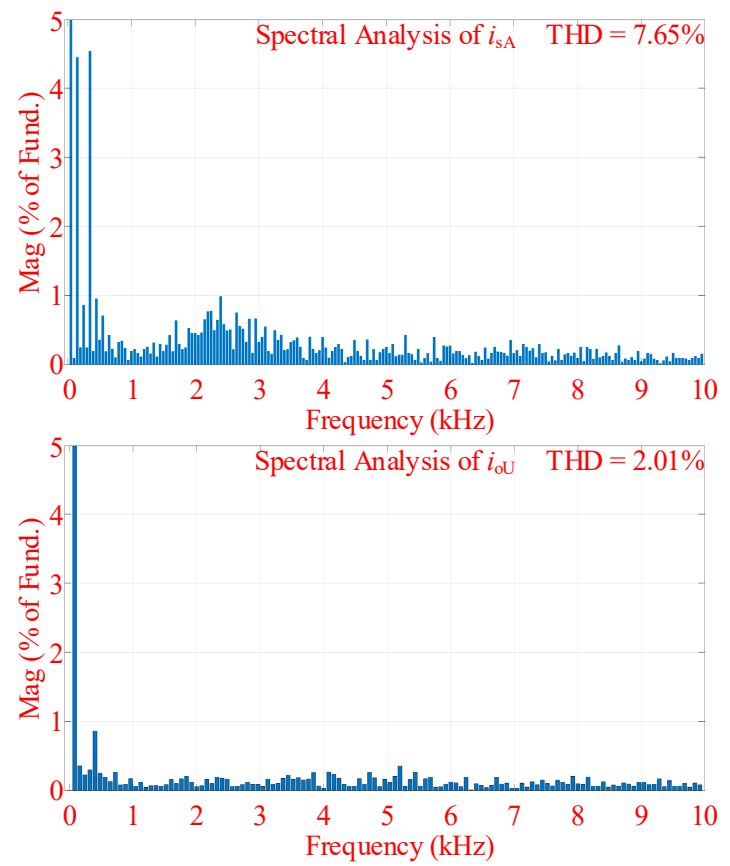

(b)

Figure 10. Experimental results of Case 5: (a) with the conventional MPC and (b) with the improved MPC. Source voltages are unbalanced and distorted. 


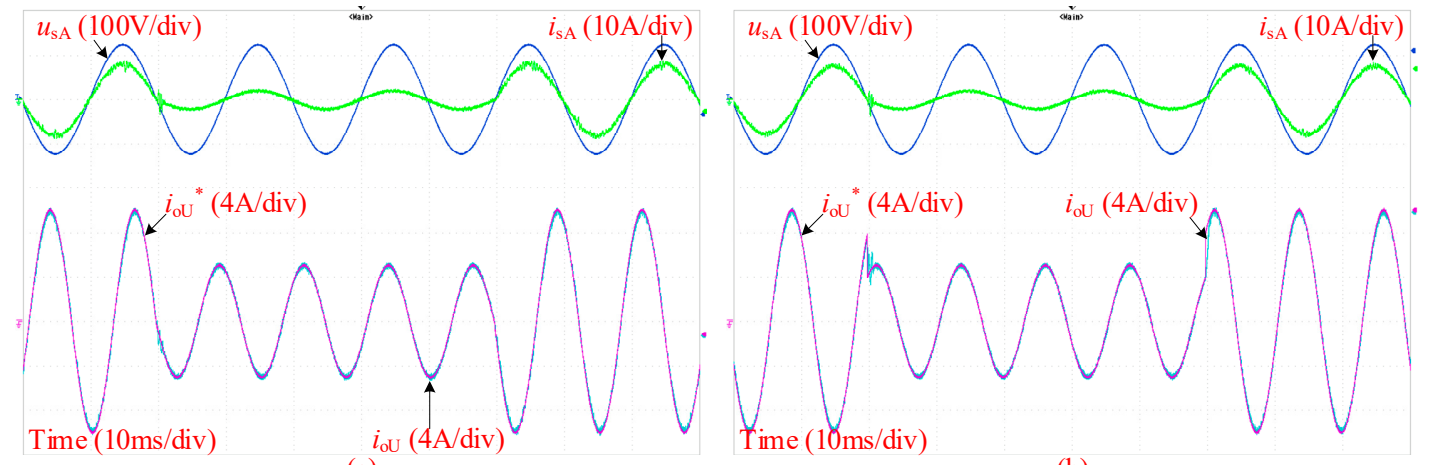

(a)

(b)

Figure 11. Experimental results of Case 6: (a) with the conventional MPC and (b) with the improved MPC. The reference amplitude of the output current steps between 10A and 5A.

\section{Conclusions}

Due to the lack of large energy storage elements, the input and output circuits of the MC interact with each other directly. Existing MPC schemes apply the delay compensation and model predictions to the input and output sides of MC separately, ignoring the interaction between the two sides. Therefore, prediction models adopted by conventional MPC schemes cannot accurately describe the MC's behavior in one sampling period. The improved MPC proposed in this paper integrates the input circuit, MC, and output circuit into one precise prediction model, which accurately characterizes the MC's behavior. Experimental results have demonstrated that the improved MPC can always obtain a better control performance under various working conditions. In turn, the filter components can be reduced if the same power quality is considered as the design criterion.

The precise prediction model proposed in this paper is also applicable to other MPC schemes for the MC so as to reduce the prediction errors and improve the power quality, but only if the cost functions are set accordingly.

Author Contributions: Conceptualization, S.F. and J.L.; methodology, J.L.; validation, C.W.; formal analysis, J.L.; resources, J.L.; data curation, C.W.; writing—original draft preparation, J.L.; writing—review and editing, S.F.; supervision, S.F. and J.L.; project administration, S.F. and J.L.; funding acquisition, S.F. and J.L.

Funding: This work was supported in part by the National Natural Science Foundation of China under Grant 51807025 and in part by the Natural Science Foundation of Jiangsu Province of China under Grant BK20180396.

Conflicts of Interest: The authors declare no conflict of interest.

\section{References}

1. Kolar, J.W.; Friedli, T.; Rodriguez, J.; Wheeler, P.W. Review of Three-Phase PWM AC-AC Converter Topologies. IEEE Trans. Ind. Electron. 2011, 58, 4988-5006. [CrossRef]

2. Tuyen, N.; Dzung, P. Space Vector Modulation for an Indirect Matrix Converter with Improved Input Power Factor. Energies 2017, 10, 588. [CrossRef]

3. Rodriguez, J.; Rivera, M.; Kolar, J.W.; Wheeler, P.W. A Review of Control and Modulation Methods for Matrix Converters. IEEE Trans. Ind. Electron. 2012, 59, 58-70. [CrossRef]

4. Gong, Z.; Zheng, X.; Zhang, H.; Dai, P.; Wu, X.; Li, M. A QPR-Based Low-Complexity Input Current Control Strategy for the Indirect Matrix Converters with Unity Grid Power Factor. IEEE Access 2019, 7, 38766-38777. [CrossRef]

5. Song, W.; Liu, J.; Sun, X.; Wu, F.; Gao, D.; Wang, Y. Research on Commutation and Coordination Control Strategy of Excitation Power Supply Based on Bidirectional Reduced Matrix Converter for Ion Accelerator. Energies 2018, 11, 3396. [CrossRef]

6. Wang, R.; Wang, X.; Liu, C.; Gao, X. A Duty Cycle Space Vector Modulation Strategy for a Three-to-Five Phase Direct Matrix Converter. Energies 2018, 11, 370. [CrossRef] 
7. Shi, T.; Wu, L.; Yan, Y.; Xia, C. Harmonic Spectrum of Output Voltage for Space Vector Pulse Width Modulated Ultra Sparse Matrix Converter. Energies 2018, 11, 390.

8. Rivera, M.; Wilson, A.; Rojas, C.A.; Rodriguez, J.; Espinoza, J.R.; Wheeler, P.W.; Empringham, L. A Comparative Assessment of Model Predictive Current Control and Space Vector Modulation in a Direct Matrix Converter. IEEE Trans. Ind. Electron. 2013, 60, 578-588. [CrossRef]

9. Vazquez, S.; Leon, J.I.; Franquelo, L.G.; Rodriguez, J.; Young, H.A.; Marquez, A.; Zanchetta, P. Model Predictive Control: A Review of Its Applications in Power Electronics. IEEE Ind. Electron. Mag. 2014, 8, 16-31. [CrossRef]

10. Zhang, J.; Norambuena, M.; Li, L.; Dorrell, D.; Rodriguez, J. Sequential Model Predictive Control of Three-Phase Direct Matrix Converter. Energies 2019, 12, 214. [CrossRef]

11. Rivera, M.; Rodriguez, J.; Espinoza, J.R.; Friedli, T.; Kolar, J.W.; Wilson, A.; Rojas, C.A. Imposed Sinusoidal Source and Load Currents for an Indirect Matrix Converter. IEEE Trans. Ind. Electron. 2012, 59, 3427-3435. [CrossRef]

12. Lei, J.; Zhou, B.; Wei, J.; Bian, J.; Zhu, Y.; Yu, J.; Yang, Y. Predictive Power Control of Matrix Converter with Active Damping Function. IEEE Trans. Ind. Electron. 2016, 63, 4550-4559. [CrossRef]

13. Shadmand, M.B.; Mosa, M.; Balog, R.S.; Abu-Rub, H. Model Predictive Control of a Capacitorless Matrix Converter-Based STATCOM. IEEE J. Emerg. Sel. Top. Power Electron. 2017, 5, 796-808. [CrossRef]

14. Wang, F.; Zhang, Z.; Davari, A.; Fotouhi, R.; Khaburi, D.; Rodriguez, J.; Kennel, R. Encoderless Predictive Torque Control by Using a Revised Prediction Model and EFOSMO. IEEE Trans. Ind. Electron. 2014, 61, 6635-6644. [CrossRef]

15. López, M.; Rodriguez, J.; Silva, C.; Rivera, M. Predictive Torque Control of a Multidrive System Fed by a Dual Indirect Matrix Converter. IEEE Trans. Ind. Electron. 2015, 62, 2731-2741. [CrossRef]

16. Siami, M.; Amiri, M.; Savadkuhi, H.K.; Rezavandi, R.; Valipour, S. Simplified Predictive Torque Control for a PMSM Drive Fed by a Matrix Converter with imposed input current. IEEE J. Emerg. Sel. Top. Power Electron. 2018, 6, 1641-1649. [CrossRef]

17. Siami, M.; Khaburi, D.A.; Rodriguez, J. Simplified Finite Control Set-Model Predictive Control for Matrix Converter-Fed PMSM Drives. IEEE Trans. Power Electron. 2018, 33, 2438-2446. [CrossRef]

18. Formentini, A.; Trentin, A.; Marchesoni, M.; Zanchetta, P.; Wheeler, P. Speed Finite Control Set Model Predictive Control of a PMSM Fed by Matrix Converter. IEEE Trans. Ind. Electron. 2015, 62, 6786-6796. [CrossRef]

19. Wang, L.; Dan, H.; Zhao, Y.; Zhu, Q.; Peng, T.; Sun, Y.; Wheeler, P. A Finite Control Set Model Predictive Control Method for Matrix Converter with Zero Common-Mode Voltage. IEEE J. Emerg. Sel. Top. Power Electron. 2018, 6, 327-338. [CrossRef]

20. Vargas, R.; Rodriguez, J.; Rojas, C.A.; Rivera, M. Predictive Control of an Induction Machine Fed by a Matrix Converter with Increased Efficiency and Reduced Common-Mode Voltage. IEEE Trans. Energy Convers. 2014, $29,473-485$.

21. Xiong, W.; Sun, Y.; Lin, J.; Su, M.; Dan, H.; Rivera, M.; Guerrero, J. A Cost-Effective and Low-Complexity Predictive Control for Matrix Converters Under Unbalanced Grid Voltage Conditions. IEEE Access 2019, 7, 43895-43905. [CrossRef]

22. Rivera, M.; Rojas, C.; Rodríguez, J.; Wheeler, P.; Wu, B.; Espinoza, J. Predictive Current Control with Input Filter Resonance Mitigation for a Direct Matrix Converter. IEEE Trans. Power Electron. 2011, 26, 2794-2803. [CrossRef]

23. Rivera, M.; Rodriguez, J.; Wu, B.; Espinoza, J.R.; Rojas, C.A. Current Control for an Indirect Matrix Converter with Filter Resonance Mitigation. IEEE Trans. Ind. Electron. 2012, 59, 71-79. [CrossRef]

24. Zhang, G.; Yang, J.; Sun, Y.; Su, M.; Zhu, Q.; Blaabjerg, F. A Predictive-Control-Based Over-Modulation Method for Conventional Matrix Converters. IEEE Trans. Power Electron. 2018, 33, 3631-3643. [CrossRef]

25. Peng, T.; Dan, H.; Yang, J.; Deng, H.; Zhu, Q.; Wang, C.; Gui, W.; Guerrero, J.M. Open-Switch Fault Diagnosis and Fault Tolerant for Matrix Converter with Finite Control Set-Model Predictive Control. IEEE Trans. Ind. Electron. 2016, 63, 5953-5963. [CrossRef] 
26. Dan, H.; Peng, T.; Su, M.; Deng, H.; Zhu, Q.; Zhao, Z.; Wheeler, P. Error-Voltage-Based Open-Switch Fault Diagnosis Strategy for Matrix Converters with Model Predictive Control Method. IEEE Trans. Ind. Appl. 2017, 53, 4603-4612. [CrossRef]

27. Yepes, A.G.; Freijedo, F.D.; Doval-Gandoy, J.; López, Ó.; Malvar, J.; Fernandez-Comesaña, P. Effects of Discretization Methods on the Performance of Resonant Controllers. IEEE Trans. Power Electron. 2010, 25, 1692-1712. [CrossRef]

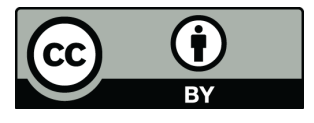

(C) 2019 by the authors. Licensee MDPI, Basel, Switzerland. This article is an open access article distributed under the terms and conditions of the Creative Commons Attribution (CC BY) license (http://creativecommons.org/licenses/by/4.0/). 